\title{
Hygrothermal performance of novel internal and external super-insulating systems: in-situ experimental study and 1D/2D numerical modeling
}

\author{
Mohamad Ibrahima, ${ }^{\mathrm{a} \mathrm{w}^{\mathrm{a}}}$, Hasan Sayegh ${ }^{\mathrm{a}}$, Lorenza Bianco ${ }^{\mathrm{a}}$, Etienne Wurtz ${ }^{\mathrm{a}}$ \\ ${ }^{\text {a } U n i v ~ G r e n o b l e ~ A l p e s, ~ C E A, ~ L I T E N, ~ D e p a r t m e n t ~ o f ~ S o l a r ~ T e c h n o l o g i e s, ~ I N E S, ~ F-38000 ~ G r e n o b l e, ~}$ \\ France \\ ${ }^{\mathrm{b}}$ University of Nice Sophia Antipolis, Department of Sustainable and Smart Buildings, Polytech'Lab \\ EA 7498, Sophia Antipolis, France
}

\begin{abstract}
The growth in population, enhancement of building services and comfort levels, together with the rise in time spent inside buildings, have raised building energy consumption. The building sector offers significant potential for improved energy efficiency through the use of highperformance insulation. In these past years, a lot of research has been carried out on super insulating insulation, particularly silica-aerogels for building application. In this study, we present an in-situ experimental assessment and a numerical modelling analysis of newly developed silica-aerogel-based insulating composite systems. The aerogel blankets, which are the core component of these systems, are obtained thanks to an innovative ambient drying process. Based on these blankets, two systems were developed: one as an external insulation and one as an internal insulation. For the internal insulation composite system, a synthetic rubber layer is present representing an integrated vapour barrier. The results of the in-field hygrothermal testing during summer and winter seasons are presented and discussed. In addition, 1D and 2D numerical models for the heat and moisture transfer across these advanced envelopes are developed and calibrated, with the identification of the most influential parameters on the model calibration. It is concluded that the models constructed using labscale measured data can lead to significant errors in the results compared to the in-situ real performance, mainly for moisture transfer. A calibration step is necessary through parametric analysis. For better and easier calibration, the numerical models should be coupled to an optimization algorithm.
\end{abstract}

Keywords: aerogel insulation; building retrofit; heat and moisture transfer; numerical model calibration; in-situ hygrothermal assessment

*Corresponding author: mohammad_ibrahim7@hotmail.com 
1. Introduction

Globally, the building sector is one of the largest energy consumers and accounts for about $43 \%$ of the total energy consumption. The growth in population, enhancement of building services and comfort levels, together with the rise in time spent inside buildings, have raised building energy consumption to the levels of transport and industry, and even more. However, the building sector offers significant potential for improved energy efficiency through the use of high-performance insulation and energy-efficient systems. When retrofitting existing building in highly-dense cities, the thickness of the applied thermal insulation becomes critical. The interest of applying super-insulating systems is the preservation of the livable space of the apartments (when considering internal thermal insulation retrofitting solution). Even though the current cost of the aerogel-based insulation is high relative to the traditional insulation, the aerogel insulation can be still cost-effective if the costs related to space savings are considered.

In these past years, a lot of research was done on super insulating insulation, particularly silicaaerogels for building application. Some studies dealt with insulating panels based on silica aerogel [1]-[5], while others dealt with aerogel based renders and mortars [6]-[10]. Yet, other studies integrated aerogel materials in some active systems such as solar thermal collectors [11], [12] or integrated some active systems in aerogel-based products [13], [14].

\subsection{Aerogel-based Products}

1.1.1. Previous literature and existing silica aerogel-based products

Given the fragility of aerogel, aerogels granules are usually embedded in a mix of a porous material. For example, aerogels are being mixed with plasters and renders to form an insulting system for interior or exterior use in buildings [7], [15]-[17] and to reduce thermal bridges [18]. These plasters have very good thermal performance (thermal conductivity between $0.026 \mathrm{~W} /(\mathrm{m} . \mathrm{K})$ and $0.028 \mathrm{~W} /(\mathrm{m} . \mathrm{K}))$, can be applied using the traditional techniques, and are flexible with respect to unevenness surfaces ensuring the continuity of the thermal insulation layer. In addition, they are permeable to water vapour in addition to being water repellant. In these recent years, there were some development of such aerogel-based plasters [8]. A commercialized aerogel-plaster (FIXIT 222) was developed at the Swiss Federal Institute EMPA [19]. It has a declared thermal conductivity of $0.028 \mathrm{~W} /(\mathrm{mK})$.

Other than aerogel-based plasters, several attempts have been carried out to develop silica aerogel-based insulating blankets/panels where the aerogels are strengthened using stronger materials such as fiber matrixes (glass, mineral or carbon fibres) [2], [4], [20].The developed products have excellent thermal resistance (thermal conductivity between $0.014 \mathrm{~W}(\mathrm{~m} . \mathrm{K})$ and $0.017 \mathrm{~W} /(\mathrm{m} . \mathrm{K})$ ). As commercial products existing nowadays, we find Spaceloft developed by 
Aspen Aerogels Inc. [21] which is a flexible fiber-reinforced blanket with a declared thermal conductivity of $0.015 \mathrm{~W} /(\mathrm{mK})$ with a water vapour diffusion resistance factor of around 5 . Spaceloft is available in $5 \mathrm{~mm}$ and $10 \mathrm{~mm}$ thickness. Another product is Thermal-Wrap ${ }^{\mathrm{TM}}$ developed by Cabot Corporation [22], available in multiple thicknesses up to $8 \mathrm{~mm}$.

Other applications is the integration of aerogels in concrete [23]-[25]. The results show that these products are unable to obtain a thermal conductivity below $0.30 \mathrm{~W} /(\mathrm{mK})$ with a compressive strength above $10 \mathrm{MPa}$ as reported by [7]. In addition, a lot of research is carried out on developing and testing aerogel-based glazing systems using monolithic aerogel or granular aerogel [26]-[29].

\subsubsection{The aerogel-based products in this study}

In this study, two silica-aerogel-based insulating composite systems are newly developed. The aerogel blankets (developed by Enersens ${ }^{1}$ company), which are the core component of these systems, are obtained thanks to an innovative ambient drying process for the aim to decrease the manufacturing process energy and costs. Unlike other available products, the aerogelblanket can have a thickness of up to $25 \mathrm{~mm}$ obtained through the manufacturing process.

Initially, a fibrous network (needle glass) is impregnated by pre-hydrolyzed Tetraethoxysilane precursors. A silica organogel is obtained by the in-situ gelation of the precursor, and the organogel is made hydrophobic by silylation with HMDSO [Hexamethyldisiloxane] in an acid medium. Finally, the composite obtained containing the fibrous network and the hydrophobic silica gel is dried. Fibers take the form of an un-woven mat with fiber diameter around $10 \mu \mathrm{m}$ and a length of few millimeters. The fraction volume fiber is in the range $1 \%-5 \%$ to limit the increase of the solid thermal conductivity by the fibers themselves and to strengthen the aerogels. More details on the blanket's characterization at material level can be found in [30] and [31].

Based on these blankets, two systems were developed: one as an external insulation system (developed and installed by Parex Group ${ }^{2}$ company) and one as an internal insulation system (developed and installed by Trocellen ${ }^{3}$ company). For the internal insulation composite system, a synthetic rubber layer is present acting as an integrated vapour barrier. This layer also enhances the wall's acoustic performance.

The objectives of this research work are to investigate the real-scale hygrothermal performance of these super insulating systems through in-field measurements and to develop hygrothermal numerical models.

\footnotetext{
1 http://enersens.fr/

2 http://www.parex-group.com/

3 https://trocellen.com/
} 


\subsection{Coupled heat and moisture transfer}

\subsubsection{Previous literature on physical models and tools}

Models to represent physical phenomena of heat and moisture transfer in porous media have been carried since the fifties, with the works of Philip and De Vries [32] [33] and Luikov [34]. The hyrothermal performance of a building can be assessed by analysing energy, moisture, and air balances. The hygrothermal balances consider the normal flows of heat by conduction, convection, and radiation; moisture flows by vapour diffusion, convection, and liquid transport; and airflows driven by natural, external, or mechanical forces. Over the last decades, several models were proposed in the literature to mathematically describe the moisture transport and for the assessment of moisture effects. A detailed review of numerical models has been reported in [35]. Since the 1990's, many computer-based tools for the prediction of the hygrothermal performance were developed, such as DELPHIN [36], MATCH [37], MOIST [38], WUFI [39], and HAM-Tools [40]. Moisture models have also been implemented in wholebuilding simulation tools and tested in the frame of the International Energy Agency Annex 41 [41].

\subsubsection{Previous literature on coupled heat and moisture transfer applied to aerogel insulation}

Concerning aerogel-based products for retrofitting opaque building facades, some research work considered just experimental testing while others carried out both experimental and numerical investigations.

As illustrations, Galiano et al. [1] examined the hygrothermal performance of a south-east oriented façade retrofitted on its inner surface by four prototype solutions including special perlite boards and aerogel composite materials. The analysis envisaged both monitoring by means of temperature, moisture and heat flux sensors at demo scale, and heat and moisture transfer modelling.

Martinez et al. [2] carried out an experimental assessment of the thermal performance of ambient pressure dried silica aerogel based composite insulation. Assessments at both material and system levels were done. Stress-strain tests, hot plate measurements, as well as full scale tests under realistic boundary conditions were conducted. The overall results showed good insulation properties (thermal conductivity in the range of $0.015-0.018 \mathrm{~W} /(\mathrm{m} . \mathrm{K})$ ), along with sufficient mechanical properties.

Lucchi et al. [42] investigated a new material based on aerogel technology as a blown-in insulation for historical buildings refurbishment. This material is a composite made from polyester fibers impregnated with silica aerogel particles. Results from laboratory tests on a 
large-scale mock-up and from a monitoring campaign in a real application on the internal wall of a historical building were discussed.

Table 1 shows a summary of some previous experimental and numerical research work on heat and moisture transfer across opaque envelopes insulated with aerogel-based materials. We considered only the experimental work at a demonstration scale (test façade in an experimental test cell) and at full-scale house (building). The studies at material scale were not considered.

Table 1: summary of some previous experimental and numerical research work on heat and moisture transfer across opaque envelopes insulated with aerogel-based materials

\begin{tabular}{|c|c|c|c|c|c|c|}
\hline work & $\begin{array}{l}\text { investigated } \\
\text { Material }\end{array}$ & $\begin{array}{l}\text { Experimental } \\
\text { work / Testing } \\
\text { scale }\end{array}$ & Façade type & $\begin{array}{l}\text { Demo or real scale } \\
\text { Testing (material } \\
\text { scale not included) }\end{array}$ & $\begin{array}{l}\text { Numerical } \\
\text { modeling / } \\
\text { Software } \\
\text { used }\end{array}$ & $\begin{array}{l}\text { Model } \\
\text { validation } \\
\text { against } \\
\text { experiential } \\
\text { results }\end{array}$ \\
\hline $\begin{array}{l}\text { Galiano } \\
\text { et al. [1] }\end{array}$ & $\begin{array}{l}\text { perlite boards } \\
\text { and aerogel } \\
\text { composite } \\
\text { materials }\end{array}$ & $\begin{array}{l}\text { Yes l } \\
\text { demonstration } \\
\text { scale (test } \\
\text { façade) }\end{array}$ & $\begin{array}{l}\text { Concrete and } \\
\text { non-load } \\
\text { bearing } \\
\text { cavity walls }\end{array}$ & $\begin{array}{ll}\text { - } & \text { In-situ thermal } \\
\text { transmittance } \\
\text { (U-value) } \\
\text { - } \quad \text { Temperature }\end{array}$ & $\begin{array}{l}\text { Yes / WUFI } \\
\text { (1D) }\end{array}$ & Yes \\
\hline $\begin{array}{l}\text { Martinez } \\
\text { et al. [2] }\end{array}$ & $\begin{array}{l}\text { Silica } \\
\text { aerogel- } \\
\text { based panels }\end{array}$ & $\begin{array}{l}\text { Yes / } \\
\text { scale (test } \\
\text { façade in } \\
\text { experimental } \\
\text { test cell) }\end{array}$ & & $\begin{array}{ll} & \text { Thermal } \\
& \text { conductivity }\end{array}$ & No & \\
\hline $\begin{array}{l}\text { Cuce } \\
\text { and } \\
\text { Cuce [3] }\end{array}$ & $\begin{array}{l}\text { Aerogel- } \\
\text { based } \\
\text { blanket }\end{array}$ & $\begin{array}{l}\text { Yes / room } \\
\text { scale }\end{array}$ & $\begin{array}{l}\text { gypsum } \\
\text { plasterboard } \\
\text { internal wall }\end{array}$ & $\begin{array}{ll}\text { - } & \text { heat flux } \\
\text { - } & \text { temperature } \\
\text { - } & \text { thermal bridge } \\
& \text { around the } \\
\text { junction of the } \\
\text { internal } \\
\text { separating } \\
\text { walls }\end{array}$ & No & \\
\hline $\begin{array}{l}\text { Lakatos } \\
{[4]}\end{array}$ & $\begin{array}{l}\text { Aerogel- } \\
\text { based } \\
\text { blanket }\end{array}$ & $\begin{array}{l}\text { Yes / test } \\
\text { chamber }\end{array}$ & Brick & $\begin{array}{ll}\text { - } & \text { thermal } \\
\text { transmittance } \\
\text { decrement } \\
\text { factor and } \\
\text { time lag } \\
\text { - heat flux }\end{array}$ & No & \\
\hline $\begin{array}{l}\text { Berardi } \\
{[7]}\end{array}$ & $\begin{array}{l}\text { aerogel } \\
\text { blanket and } \\
\text { aerogel- } \\
\text { enhanced } \\
\text { concrete }\end{array}$ & $\begin{array}{l}\text { Yes / building } \\
\text { scale }\end{array}$ & $\begin{array}{l}\text { Brick and } \\
\text { stone }\end{array}$ & $\begin{array}{ll}- & \text { thermal } \\
& \text { transmittance } \\
\text { - } & \text { energy } \\
& \text { consumption }\end{array}$ & $\begin{array}{l}\text { Yes / WUFI } \\
(1 D) \quad \text { and } \\
\text { EnergyPlus }\end{array}$ & No \\
\hline $\begin{array}{l}\text { Lucchi } \\
\text { et al. } \\
{[42]}\end{array}$ & $\begin{array}{l}\text { aerogel- } \\
\text { based as } \\
\text { blown-in } \\
\text { insulation }\end{array}$ & $\begin{array}{lr}\text { Yes / } & \text { demo } \\
\text { scale } & \text { (test } \\
\text { façade), and } \\
\text { real house } \\
\text { scale }\end{array}$ & $\begin{array}{l}\text { Masonry wall } \\
\text { / stone } \\
\text { masonry }\end{array}$ & $\begin{array}{ll}\text { - } & \text { In-situ thermal } \\
\text { - } & \text { transmittance } \\
\text { - } & \text { Heat flux } \\
& \text { temperatures }\end{array}$ & No & \\
\hline $\begin{array}{l}\text { lbrahim } \\
\text { et al. } \\
{[43]}\end{array}$ & $\begin{array}{l}\text { Aerogel- } \\
\text { based render }\end{array}$ & $\begin{array}{l}\text { Yes / demo } \\
\text { scale }\end{array}$ & $\begin{array}{l}\text { Heavy weight } \\
\text { concrete }\end{array}$ & $\begin{array}{ll}- & \text { Relative } \\
& \text { humidity }\end{array}$ & $\begin{array}{l}\text { Yes / WUFI } \\
\text { (1D) }\end{array}$ & Yes \\
\hline
\end{tabular}




\begin{tabular}{|c|c|c|c|c|c|c|}
\hline & & & & - temperatures & & \\
\hline $\begin{array}{l}\text { Wernery } \\
\text { et al. } \\
{[44]}\end{array}$ & $\begin{array}{l}\text { Bricks filled } \\
\text { with aerogels }\end{array}$ & $\begin{array}{lr}\text { Yes } / & \text { Small } \\
\text { scale } & \text { guarded } \\
\text { hot } & \text { plate } \\
\text { device } & \\
\end{array}$ & brick & $\begin{array}{ll}\text { - } & \text { thermal } \\
& \text { conductivity }\end{array}$ & $\begin{array}{ll}\text { Yes } & \text { / } \\
\text { BISCO }\end{array}$ & No \\
\hline $\begin{array}{l}\text { Masera } \\
\text { et al. } \\
{[45]}\end{array}$ & $\begin{array}{l}\text { aerogel- } \\
\text { impregnated } \\
\text { fabric mat }\end{array}$ & $\begin{array}{l}\text { Yes / room } \\
\text { scale }\end{array}$ & $\begin{array}{l}\text { unventilated } \\
\text { cavity hollow } \\
\text { brick }\end{array}$ & $\begin{array}{ll}\text { - } & \text { heat flux } \\
\text { - } & \text { relative } \\
& \text { humidity } \\
\text { - } & \text { temperature }\end{array}$ & No & \\
\hline $\begin{array}{l}\text { Wakili et } \\
\text { al. [46] }\end{array}$ & $\begin{array}{l}\text { Aerogel- } \\
\text { based } \\
\text { rendering }\end{array}$ & $\begin{array}{l}\text { Yes / building } \\
\text { scale }\end{array}$ & $\begin{array}{l}\text { prefabricated } \\
\text { concrete } \\
\text { panels }\end{array}$ & $\begin{array}{ll}- & \text { in-situ U-value } \\
- & \text { heat flux and } \\
& \text { temperature }\end{array}$ & $\begin{array}{l}\text { Yes / WUFI } \\
\text { (1D) }\end{array}$ & No \\
\hline $\begin{array}{l}\text { Stahl et } \\
\text { al. [47] }\end{array}$ & $\begin{array}{l}\text { Aerogel- } \\
\text { based } \\
\text { rendering }\end{array}$ & $\begin{array}{l}\text { Yes / house } \\
\text { scale }\end{array}$ & stone & $\begin{array}{ll}- & \text { U-value } \\
- & \text { Relative } \\
& \text { humidity }\end{array}$ & $\begin{array}{l}\text { Yes / WUFI } \\
\text { (1D) }\end{array}$ & No \\
\hline $\begin{array}{l}\text { The } \\
\text { current } \\
\text { work }\end{array}$ & $\begin{array}{l}\text { Aerogel- } \\
\text { based } \\
\text { blankets and } \\
\text { systems } \\
\text { (ETICS and } \\
\text { internal } \\
\text { insulation } \\
\text { system) }\end{array}$ & 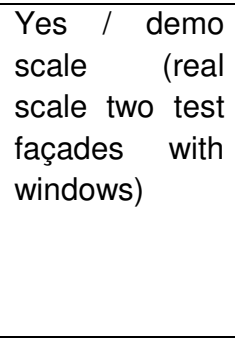 & $\begin{array}{l}\text { Concrete } \\
\text { hollow block }\end{array}$ & $\begin{array}{ll}- & \text { heat flux } \\
\text { - } & \text { temperature } \\
\text { - } & \text { relative } \\
& \text { humidity } \\
\text { - } & \text { window's } \\
\text { reveal thermal } \\
\text { bridge }\end{array}$ & $\begin{array}{l}\text { Yes / WUFI } \\
\text { (1D \& 2D) }\end{array}$ & Yes \\
\hline
\end{tabular}

\subsection{Contribution and research objectives}

In this study, we present an in-situ experimental assessment and a numerical modelling analysis of two newly developed silica-aerogel-based insulating composite systems which, as mentioned earlier, are based on aerogel blankets manufactured using an innovative process to decrease energy use and therefore decrease the production and the final cost of the insulating systems.

The objectives of the current research are:

- To perform real-scale in-situ testing on the super insulating systems through in-field hygrothermal performance characterisation during summer and winter seasons by means of performance indexes. The constructed facades include windows and are exterior facades of two test cells.

- to calibrate/validate 1D and 2D heat and moisture transfer numerical models using the experimental data monitored in field, and identify the most influential parameters on the model calibration

This work investigates the in-situ performance of the newly developed aerogel systems under real outside conditions. The purpose is to validate the previously measured properties at lab scale. In addition, and unlike other studies, the temperature and relative humidity are measured 
and monitored within the cross section of the test facades. In addition, these measurements are monitored at different heights of the wall to account for thermal/moisture bridges created by the window reveals and the ground contact. Numerical models for heat and moisture transfer are developed for $1 \mathrm{D}$ and 2D cases and validated against experimental data. The most influencing parameters on model calibration, especially for moisture transfer, are presented.

\section{Experimental methods and protocols}

\subsection{Systems installation}

The in-situ hygrothermal performance characterisation of the systems is carried out in the "FACT" test facility (Figure 1) [48] at CEA-INES, at Le Bourget du Lac, a research platform in the South-East of France.

"FACT" is designed to perform measurements of energy performance and impact of the building envelope on the indoor environment in real scale. The facility is two-floors building with a total height of $8.34 \mathrm{~m}$, and external gross dimension of $7.8 \mathrm{~m} \times 9.8 \mathrm{~m}$. It consists of 10 test cells. An HVAC system with a reversible heat pump maintains the indoor air temperature in the test cells at the desired set-point $\left( \pm 0.5^{\circ} \mathrm{C}\right)$. The indoor relative humidity is not controlled. The air flow rate, in the range of $0.5 \mathrm{vol} / \mathrm{h}$ and $3 \mathrm{vol} / \mathrm{h}$, can be set in each test cell using a mechanical ventilation system.

Two north oriented test cells were selected for the systems testing in order to avoid measurement errors caused by solar radiation. Test cells 1 and 2 are used in this study. The area of the tested facade is $7.70 \mathrm{~m}^{2}(2.3 \mathrm{~m}$ width $\times 3.3 \mathrm{~m}$ height). For each test cell, a concrete hollow block wall of $20 \mathrm{~cm}$ thickness with a wooden-frame window was constructed. The window has dimensions of $1200 \times 900 \mathrm{~mm}$ (length $\mathrm{x}$ height) and is located $1300 \mathrm{~mm}$ from the test cell's floor level. This wall construction represents an existing wall to be retrofitted, and it is a widely traditional construction technique found in several countries, particularly in France. 

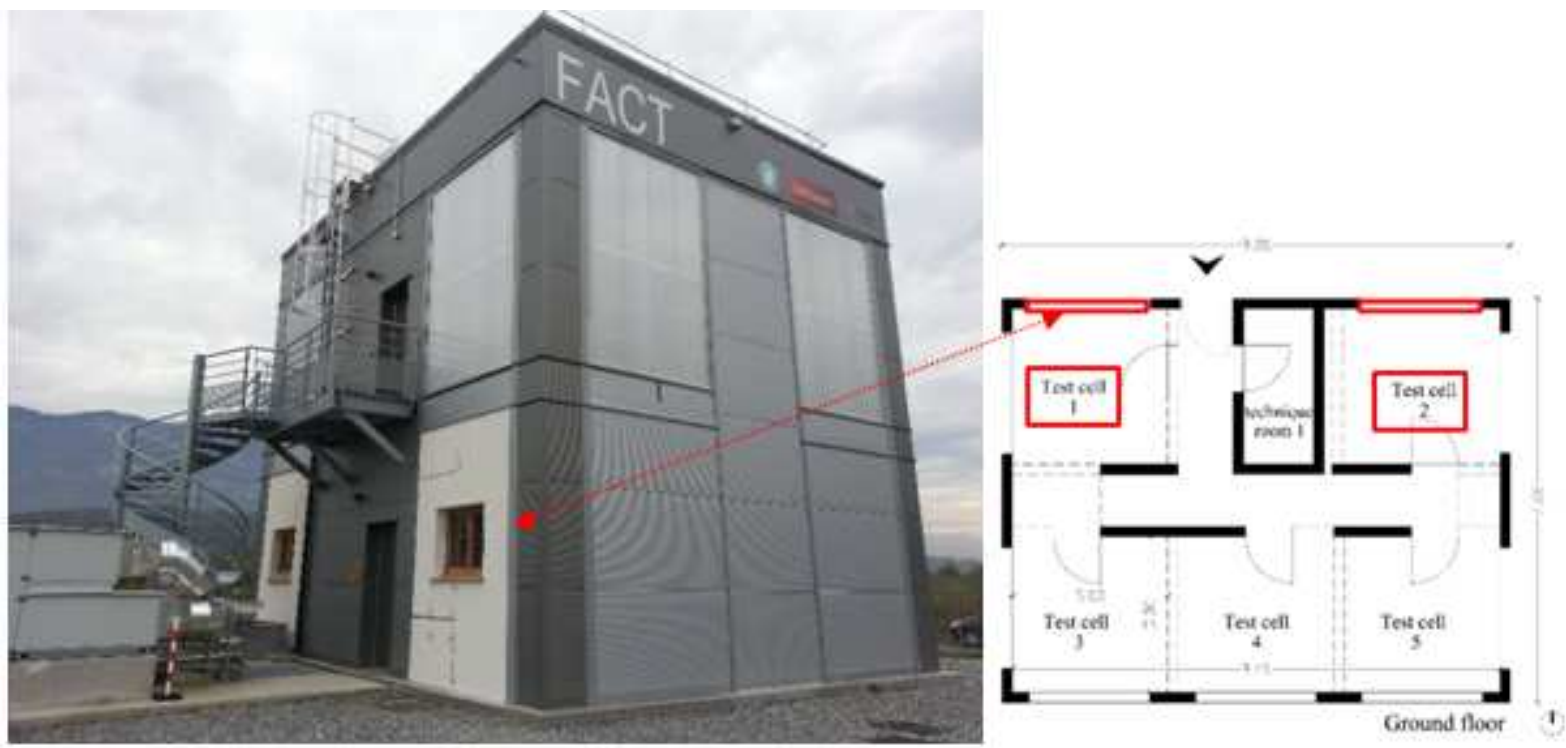

Figure 1: The test cells/facades used in this study in the FACT test facility

Test-cell 1 is used to test and validate the external thermal insulation system. The Advanced Aerogel-Based Composite (we will refer to it hereafter as AABC) multilayer system is applied to retrofit the concrete wall at the exterior side. Figure 2 gives an illustration of the proposed ETICS (External thermal insulation composite system) with AABC system starting from existing wall.

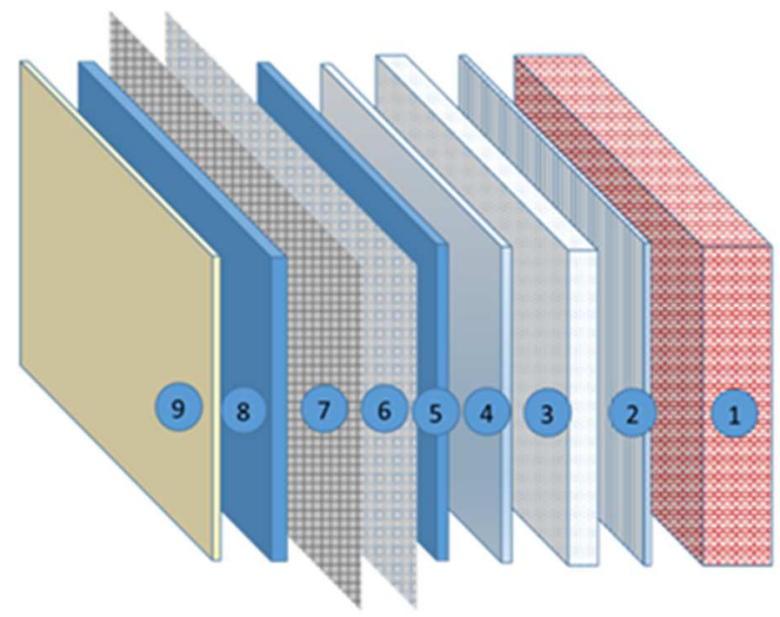
1: wall to insulate
2: adhesive mortar
3: aerogel panel $(20 \mathrm{~mm})$
4: primer
5: first coat of basecoat
6: standard glass mesh
7: reinforced glass mesh
8: second coat of basecoat
9: finishing mortar

Figure 2: The external insulation $A A B C$ system

Test-cell 2 is used to test and validate the AABC internal thermal insulation system. The AABC system is applied to retrofit the concrete wall at the interior side. Figure 3 shows the developed indoor insulation stratigraphy, starting from the existing wall. The internal thermal insulation system includes a synthetic rubber layer acting as an integrated vapor barrier and as an acoustic layer as well. 




Figure 3: The internal insulation AABC system

2.2. In field characterisation of the systems

The performance of the multi-layer AABC systems may not be similar to that measured at labscale due to several conditions including:

- The dynamic boundary conditions to which the AABC systems will be subjected to

- The inhomogeneity of the materials when it is constructed on-site

- effects of workmanship issues

- geometrical discontinuities

- effects of air infiltration, moisture migration

Reliable in situ thermal characterization allows studying the actual thermal performance of building components rather than the theoretical performance calculated from thermal properties of the constituent material layers.

The main challenge of characterizing the building components from on-site measurements is the presence of outdoor weather conditions. As the outdoor climate is intrinsically dynamic, it will complicate the estimation of a stationary parameter such as the thermal resistance.

The most generally accepted method for the in situ thermal characterization of building components is the average method, described in ISO 9869 [49]. This method estimates the thermal resistance of a building component from measurements of the heat flow rate through the internal face of the component and from measurements of the (air or surface) temperatures on both sides of the component. Essentially, the average method is based on stationary boundary conditions; thus, for the method to be valid, the averages should be taken over a sufficiently long period of time. 
The objective is to calculate the in-situ thermal conductance, $\Lambda$-value (or thermal resistance $R$ $=1 / \Lambda$ ), using the on-site measurements. This is obtained by dividing the mean density of the heat flow rate by the mean temperature difference across the envelope, the average being taken over a long enough period as shown in equation (1). The $U$-value can then be obtained by adding the resistance of the inside and outside convective films to the overall thermal conductance of the wall.

$$
\Lambda=\frac{1}{R}=\frac{\sum_{j=1}^{n} q_{j}}{\sum_{j=1}^{n}\left(T_{s i j}-T_{s e j}\right)}
$$

with $\Lambda$ the total thermal conductance of the element $\left(\mathrm{W} \cdot \mathrm{m}^{-2} \cdot \mathrm{K}^{-1}\right), T_{\text {sij }}$ the internal surface temperature at reading $j\left({ }^{\circ} \mathrm{C}\right), T_{s e j}$ the external surface temperature at reading $j\left({ }^{\circ} \mathrm{C}\right), q_{j}$ the internal heat flow rate at reading $j\left(\mathrm{~W} / \mathrm{m}^{2}\right)$ and $n$ the number of measured data points (-).

The conditions to satisfy the accuracy and the applicability of this method are more detailed in the ISO 9869:2014 standard.

In addition to the in-situ $\Lambda$-value calculation, other parameters are examined:

- The relative humidity and temperature gradients across the cross-section of the walls. The study will allow to examine the risk of water vapour condensation within the wall and consequently the risk of mould growth. These risks can be due to the multilayered wall systems themselves or due to bad workmanship when applied on-site.

- The relative humidity and temperature gradients along the height of the walls at different positions. The influence of thermal bridges can be then examined

- Heat flux at the internal wall surface which allows to estimate the heat losses/gains

\subsection{Instrumentation}

\subsubsection{What to measure?}

The following parameters are measured all along the measurement campaign:

- Boundary conditions

- Air temperature and relative inside the test cells

- Outside weather conditions (temperature, humidity, radiation, rain, wind speed and direction, etc.)

- Inside the test walls

- Temperature at different positions inside the test walls and at the interior and exterior surfaces 
- Heat flux at the interior surface for the two test walls and the heat flux behind the AABC panels

- Relative humidity at different positions inside the test walls and near the interior and exterior surfaces

\subsubsection{Sensors in the test walls}

In each test wall, several hygrothermal sensors were installed at different positions: $0.1 \mathrm{~m}$, $0.6 \mathrm{~m}, 1.2 \mathrm{~m}$, and $2.6 \mathrm{~m}$ above the test cell's floor level (Figure 4). At each position, several sensors were installed in the cross-section of the walls as shown in the same figure. Heat flux sensors were placed at the interior surface and at the interface between the aerogel insulation system and the concrete block.

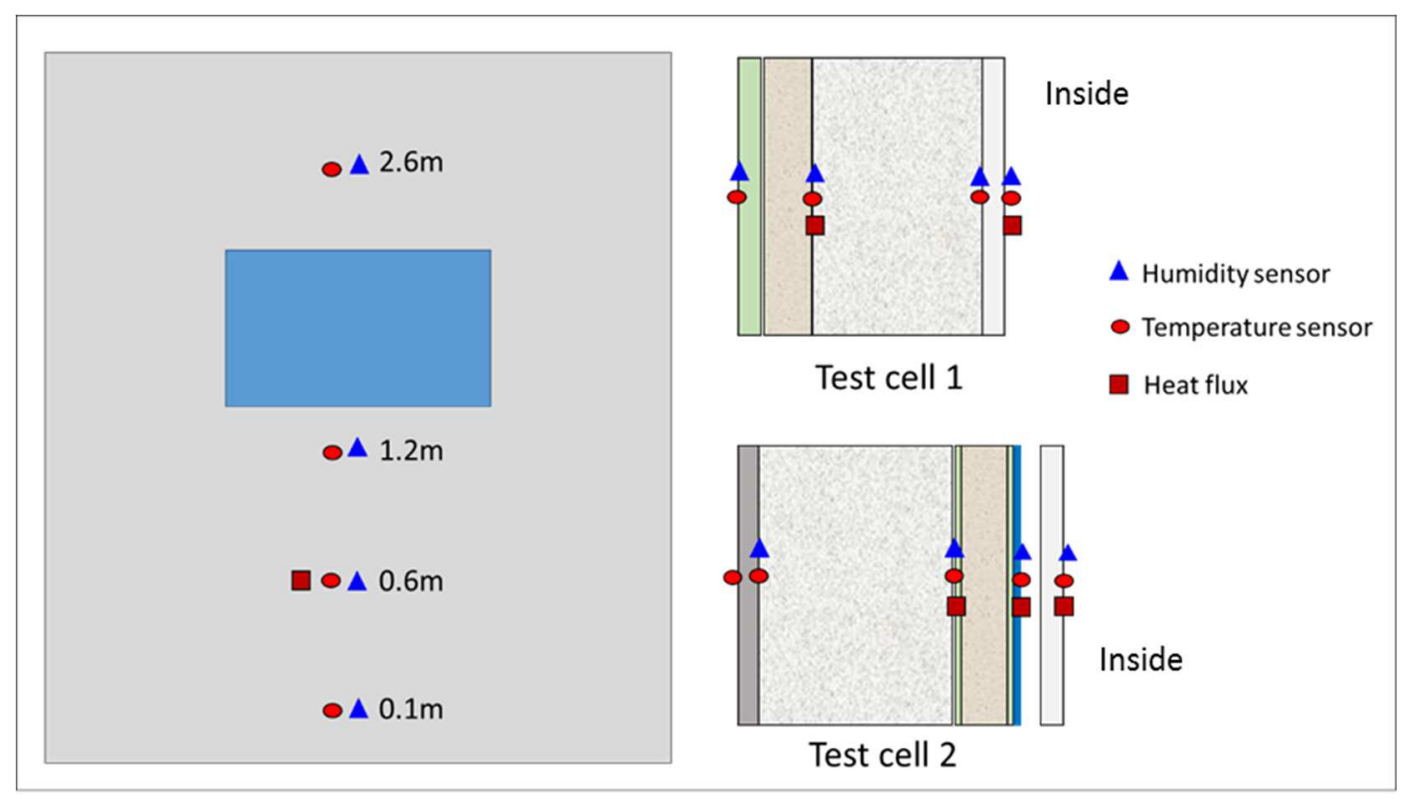

Figure 4: the sensors in each test wall

The hygrothermal sensors are of type SHT75, from Sensirion [50]. The accuracy given by the manufacturer is $\pm 1.8 \%$ for relative humidity and $\pm 0.5^{\circ} \mathrm{C}$ for temperature. To ensure a better accuracy through a better contact between the temperature sensor and the wall surface, thermocouples of type-T (copper-constantan) are also installed. They can be used for temperature measurements in the range $-270^{\circ} \mathrm{C}$ to $400^{\circ} \mathrm{C}$ with an accuracy of $\pm 0.4^{\circ} \mathrm{C}$. The heat flux meters are manufactured by Wimesure [51]. They are of square-shape, $120 \mathrm{~mm}$ side, with a thickness of the order of $1.5 \mathrm{~mm}$ with a declared uncertainty of $5 \%$.

\subsubsection{Weather station}

A weather station is installed at the experimental field to measure all the environmental inputs needed for the experimental measurements as well as for the dynamic thermal simulations. 
These include the solar radiation, air temperature and relative humidity, long-wave radiation intensity, and wind speed and direction.

3. Experimental results

3.1. Thermal conductance ( $\Lambda$-value) of the systems

For both test cells, we calculated two $\Lambda$-values

- $\Lambda$-value for the whole envelope ( $\Lambda$-cell-1-wall, $\Lambda$-cell-2-wall): in this calculation, we consider the temperature measurements of those at the interior and exterior wall surfaces, and the heat flux measurement of that at the interior wall surface as shown Figure 5.

- $\quad \Lambda$-value for the AABC system only ( 1 -cell-1-AABC, $\Lambda$-cell-2-AABC): in this calculation, we consider the temperature measurements of those at the boundary of the AABC system, and the heat flux measurement behind the AABC system as shown in the same figure.


Figure 5: sensors used for the $\Lambda$-value calculation of the entire envelope (left) and of only the AABC system (right) for test-wall-1 (top) and for test-wall-2 (bottom)

Applying equation (1), the $\Lambda$-value for the whole structure and the $\Lambda$-value for the $A A B C$ systems of both test walls are calculated and are shown in Figure 6 for a period of around 55 
days. The period is selected to obtain a considerable thermal gradient between the indoor and the outdoor environments.

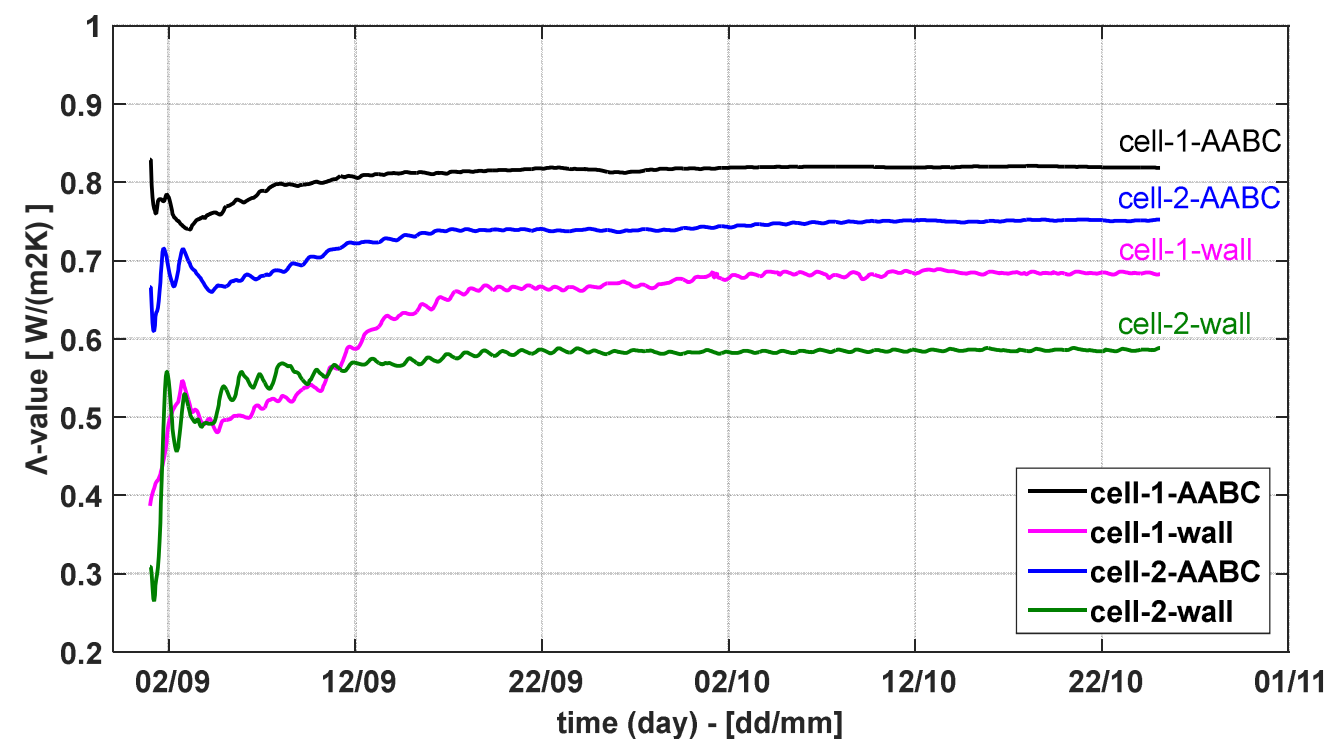

Figure 6: Thermal conductance, $\Lambda$-value, convergence

It is illustrated from the above figure that the $\Lambda$-value calculation reaches convergence to the values shown in Figure 7.

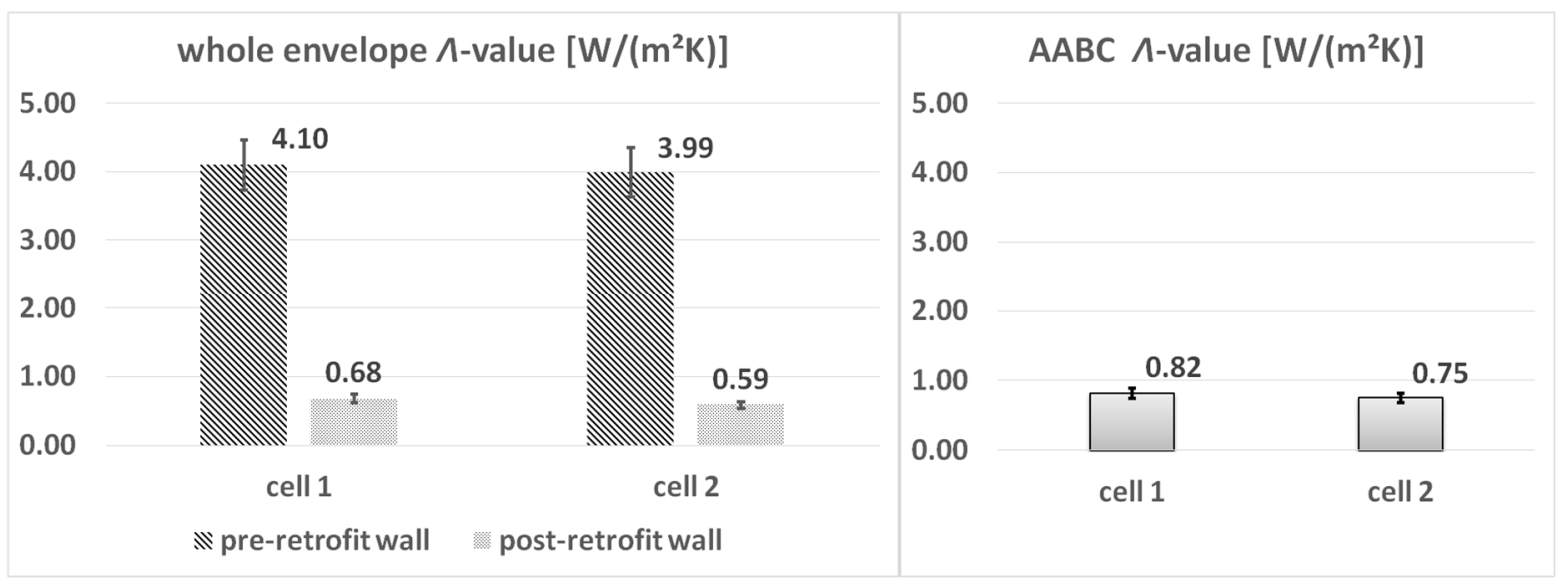

Figure 7: $\Lambda$-value of the pre and post-retrofit walls and the $\Lambda$-value for the AABC systems

The $\Lambda$-value of the pre-retrofit wall (before applying the aerogel insulation) is calculated from the thermal resistance of the whole envelope and the thermal resistance of the $A A B C$ insulation as shown in Eq. (2)

$$
\Lambda_{\text {pre-retrofit }}=\frac{1}{R}=\frac{1}{\frac{1}{\Lambda_{\text {post-retrofit }}}-\frac{1}{\Lambda_{A A B C}}}
$$

As illustrated in Figure 7, adding the AABC system of only $2 \mathrm{~cm}$ reduces the envelope's thermal transmittance of more than $80 \%$. By determining the in-situ $\Lambda$-value of the AABC system, we 
can estimate the in-situ thermal conductivity of the aerogel-panels (Table 2). For test-cell-1, the $A A B C$ is composed of the aerogel-panel and the exterior render. For test-cell-2, the AABC system is composed of a layer of aerogel-panel of $2 \mathrm{~cm}$ thickness, 2 layers of cross-lined polyethylene (PE) of $3 \mathrm{~mm}$ thickness each, and a layer of synthetic rubber of $2 \mathrm{~mm}$ thickness. The thermal conductivity of all these layers were measured at lab-scale at the Materials Testing Institute (MPA) at the University of Stuttgart and at PERSEE centre, a joint centre ARMINES/Mines ParisTech in Sophia Antipolis, France. If we use the lab-scale values for all the layers except the aerogel-panel, the in-situ thermal conductivity of the aerogel-panel can be determined.

Table 2: lab-scale and in-situ thermal conductivity measurement of the aerogel insulation

\begin{tabular}{|c|c|c|c|c|c|c|c|}
\hline & \multicolumn{2}{|c|}{$\begin{array}{l}\text { Test-cell } 1 \\
\text { (Exterior insulation) }\end{array}$} & & \multicolumn{4}{|c|}{$\begin{array}{l}\text { Test-cell } 2 \\
\text { (interior insulation) }\end{array}$} \\
\hline & $\begin{array}{l}\text { Exterior } \\
\text { render } \\
\text { (lab } \\
\text { scale) }\end{array}$ & $\begin{array}{l}\text { Aerogel } \\
\text { panel } \\
\text { (lab } \\
\text { scale) }\end{array}$ & $\begin{array}{l}\text { Aerogel panel } \\
\text { (in-situ) }\end{array}$ & $\begin{array}{l}\text { PE } \\
\text { (lab } \\
\text { scale) }\end{array}$ & $\begin{array}{l}\text { Rubber } \\
\text { (lab } \\
\text { scale) }\end{array}$ & $\begin{array}{l}\text { Aerogel } \\
\text { panel } \\
\text { (lab } \\
\text { scale) }\end{array}$ & $\begin{array}{l}\text { Aerogel } \\
\text { panel } \\
\text { (in-situ) }\end{array}$ \\
\hline $\begin{array}{l}\text { Thermal } \\
\text { conductivity } \\
{[\mathrm{W} /(\mathrm{m} \cdot \mathrm{K})]}\end{array}$ & 0.7 & 0.0165 & 0.0171 & 0.036 & 0.587 & 0.0165 & 0.0179 \\
\hline
\end{tabular}

3.2. Moisture profiles

3.2.1. Long-term performance

By setting different scenarios for the air temperature set-point inside the test cells and by adding moisture sources inside, we can examine the facades' performance, for various situations normally encountered in buildings. These scenarios are shown on Figure 8 . The free-floating scenario means that neither cooling nor heating is applied inside the test cells. The moisture generation scenario means that moisture is added inside the test walls 5 hours per day. The quantity of moisture was not controlled, but it was high enough to raise the inside air relative humidity to more than $75 \%$.

The relative humidity $(\mathrm{RH})$ at the cross section of the wall at position $0.6 \mathrm{~m}$ (refer to Figure 4 for positions) for test cell 1 is shown in Figure 8. The RH behind (seen from outside) the AABC system (position D) fluctuates between $60 \%$ and $80 \%$ in almost most of the considered period. The $\mathrm{RH}$ rise up to reach $90 \%$ is observed in the summer cooling scenario when the interior air temperature is fixed at $18^{\circ} \mathrm{C}$. The indoor air, relatively, low temperature in addition to the presence of thermal insulation at the exterior side causes the temperatures in the wall to, relatively, drop down. Although this scenario is not so realistic in the cooling season, we performed it to examine the envelope's behaviour and to check whether very high $\mathrm{RH}$ could be observed or not. In all the considered period, the daily $\mathrm{RH}$ at position $\mathrm{D}$ fluctuates between 
a maximum value and a minimum value and the range is around $10 \%$ to $15 \%$ between daytime and night-time. The $\mathrm{RH}$ at position $\mathrm{C}$ (inside the air hole of the concrete block) shows very little fluctuations and the values remain less than $80 \%$ for all the period.



Figure 8: Relative humidity across the cross-section of test wall 1 at height $0.6 \mathrm{~m}$

The relative humidity at the cross section of the wall at position $0.6 \mathrm{~m}$ for test cell 2 is shown in Figure 9. The $\mathrm{RH}$ behind (seen from inside) the $A A B C$ system (position $B$ ) remains almost stable with very little fluctuations in all considered period. During the first free-floating scenario and during the $18^{\circ} \mathrm{C}$ scenario, the $\mathrm{RH}$ at position $\mathrm{B}$ ranges between $82 \%$ and $87 \%$. During the other scenarios, the $\mathrm{RH}$ ranges between $80 \%$ and $84 \%$. The $\mathrm{RH}$ at position $\mathrm{C}$ is very close to that of position $\mathrm{B}$. It is to be noted that we drilled a hole in the concrete block from the inside and the sensor is dragged inside; therefore, we couldn't specify the exact position of the sensor inside the concrete block, and by examining the two curves it is possible that the two sensors at $B$ and at $C$ are very close. In such retrofitting cases, where thermal insulation is add to the inside surface, the risk of high moisture accumulation behind the insulation is usually high because the original wall structure becomes exposed to the outside cold environment and the heat received from the inside environment is highly reduced due to insulation. In the case here in this study, the $\mathrm{RH}$ remains below $85 \%$ in most of the measurement period. We can conclude that the risk of condensation and the risk of mould growth are minimal in this case. 


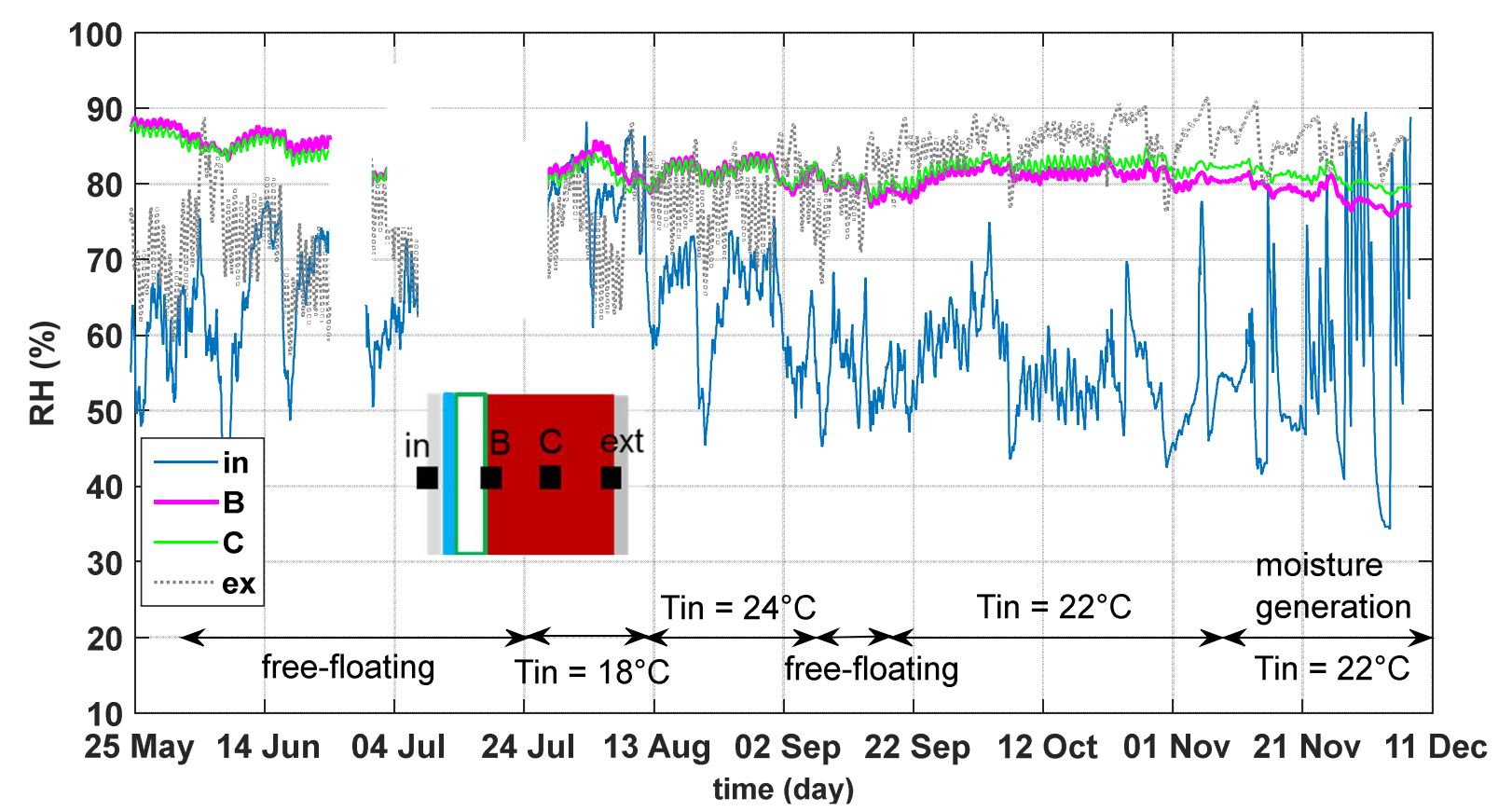

Figure 9: Relative humidity across the cross-section of test wall 2 at height $0.6 \mathrm{~m}$

\subsubsection{Influence of the thermal/moisture bridges}

Two thermal bridges are present in the tested walls. One is due to the presence of the ground and another one due to the presence of the window.

Starting with test cell 1, the $\mathrm{RH}$ and temperature profiles at different heights across the wall for position $\mathrm{C}$ are shown in Figure 10. We have chosen a period during the heating scenario (Tin $=22^{\circ} \mathrm{C}$ ). As illustrated Figure 10, the temperature profiles at positions $0.6 \mathrm{~m}$ and $1.2 \mathrm{~m}$ behave quite similarly with a difference of around $0.5^{\circ} \mathrm{C}$ which is within the uncertainty of the sensor's measurement. This is quite expected as both positions are at a centre position somehow far from thermal bridges. These temperatures show low fluctuations between day and night times with a difference of around $1{ }^{\circ} \mathrm{C}$. The temperatures at positions $0.1 \mathrm{~m}$ (near the ground) and $1.2 \mathrm{~m}$ (near the window reveal) are lower than those of the $0.6 \mathrm{~m}$ and $2.6 \mathrm{~m}$ positions; the difference can reach up to $2^{\circ} \mathrm{C}$ at night time. In addition, these temperatures show more fluctuations during the day with a range that can reach up to $2.5^{\circ} \mathrm{C}$. It is to be noted that a thin layer of $7 \mathrm{~mm}$ thickness of the aerogel-insulation was applied on all the window reveals to reduce the heat losses of this thermal bridge. By comparing the temperatures at positions $0.6 \mathrm{~m}$ and $1.2 \mathrm{~m}$ (near the window reveal thermal bridge), we can deduce that the difference is not so high verifying the performance of this thin layer of aerogel to reduce heat losses. Concerning the $\mathrm{RH}$, very high $\mathrm{RH}$ humidity values are observed for the $0.1 \mathrm{~m}$ position. This can be explained due to two factors: the thermal bridge and the capillary suction of moisture from the ground. The $\mathrm{RH}$ near the window is higher than that at the centre of the wall by around $10 \%$ 
which could be attributed to the lower temperatures due to the thermal bridge and maybe due to some moisture bridges also. The $\mathrm{RH}$ and temperatures at positions $0.6 \mathrm{~m}$ and $1.2 \mathrm{~m}$ for the whole analysed period is shown in Figure 11. We can conclude that the $\mathrm{RH}$ at this position is below $80 \%$ most of the time meaning lower risks of mould growth and condensation issues.
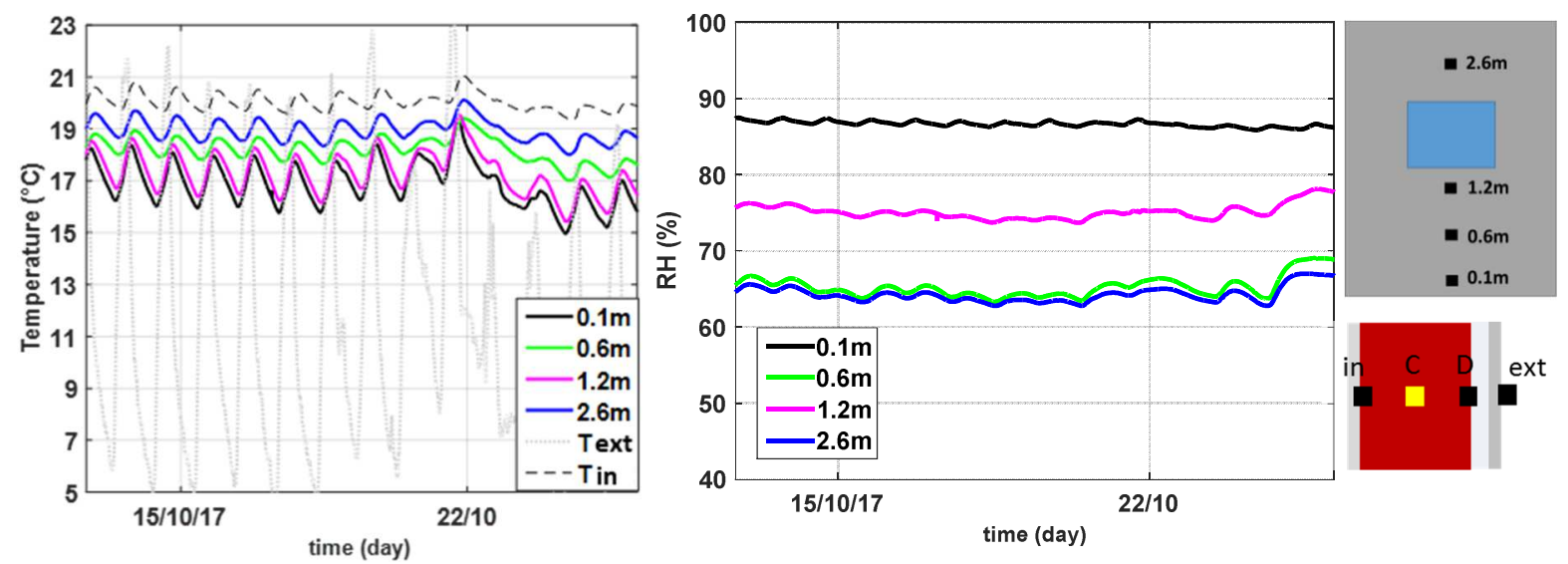

Figure 10: Temperature (left) and relative humidity (right) profiles at position $\mathbf{C}$ at different heights for a specific period in test wall 1
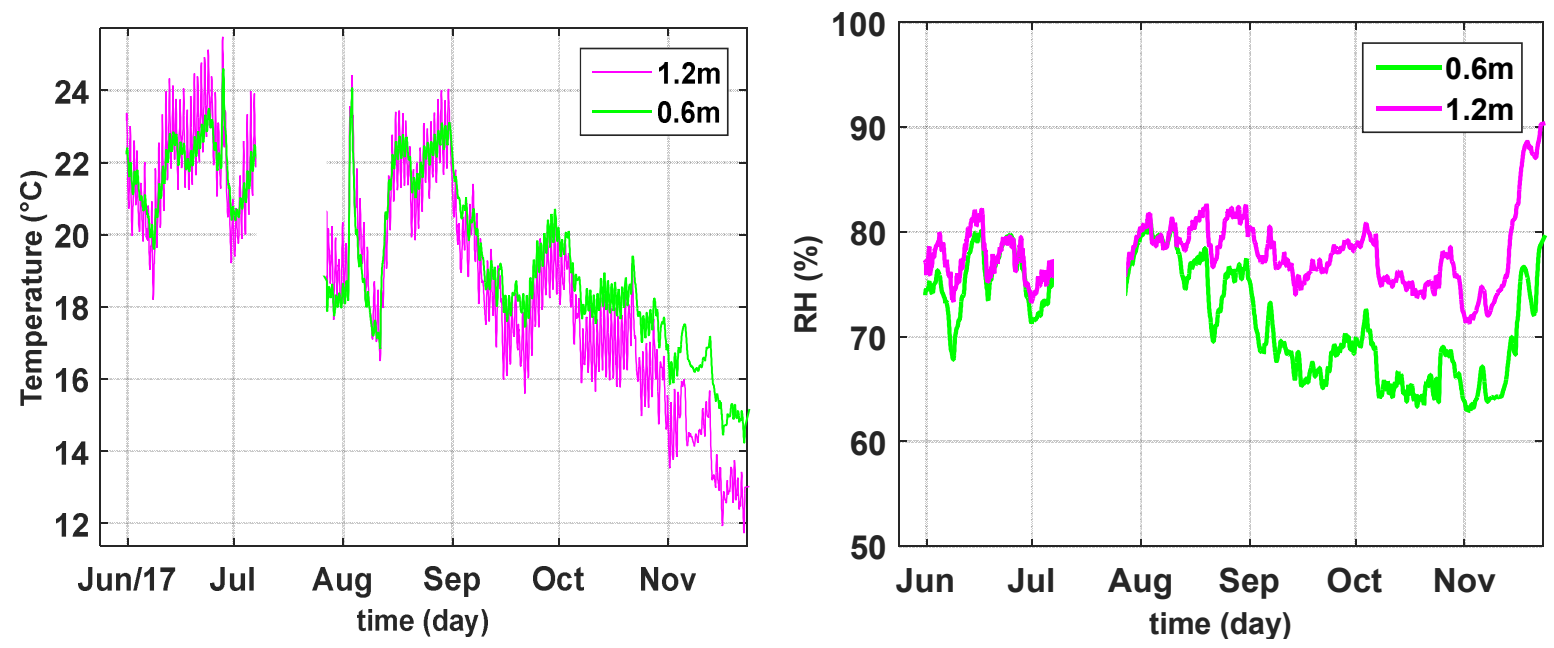

Figure 11: Temperature (left) and relative humidity (right) profiles at position $\mathrm{C}$ at heights $0.6 \mathrm{~m}$ and $1.2 \mathrm{~m}$ for the whole period for test wall 1

Moving to test cell 2, the $\mathrm{RH}$ and temperature profiles at different heights across the wall for position $\mathrm{C}$ are shown in Figure 12. The temperature profiles at positions $0.6 \mathrm{~m}$ and $1.2 \mathrm{~m}$ behaves quite similarly.

Concerning the $\mathrm{RH}$, very high $\mathrm{RH}$ humidity values are observed for the $0.1 \mathrm{~m}$ position. This can be explained mainly due to the capillary suction of moisture from the ground. The $\mathrm{RH}$ near the window reveal is higher than that at the centre of the wall by around $10 \%$. 



Figure 12: Temperature (left) and relative humidity (right) profiles at position $C$ at different heights in test wall 2

\subsubsection{Mould growth assessment}

Different mould growth prediction models are found in the literature. Some are simple qualitative models (Time of wetness, RHT index, ASHRAE standard-160 method) and others are more quantitative models (VTT model). Each of these models includes however different simplifications or is based on different assumptions. Vereecken and Roels [52] carried out an extensive review of the mould growth prediction models found in the literature presenting the drawbacks of each of them based on the simplified assumptions used or the methodology followed. They concluded that more in-depth study of the mould growth, especially, under transient conditions is still necessary through undertaking additional measurements in lab conditions as well as in real ones.

In this study, we choose two indexes. The RH85 and the VTT model to assess the envelope moisture performance. $\mathrm{RH} 85$ is the number of hours where the $\mathrm{RH}$ at a specific position exceeds $85 \%$. The VTT model is a dynamic model that takes into account the influence of temperature, relative humidity, surface material, exposure time and dry periods. In these methods, we are based on some assumptions, therefore it is not possible to predict whether mould will grow or not because the mould growth depends on serval parameters. In this sense, both methods are used to give us an idea whether there may be a mould growth risk or not. The higher the numbers are, the higher is the risk.

The VTT model is a dynamic model which was developed by Viitanen [53] at the VTT Technical Research Center of Finland. It is an empirical mould prediction model in which the growth development is expressed by the mould index $(M)$. This index ranges between 0 and 6 , and can be used as a design criterion, for e.g. a mould index equals to 1 is often defined as the maximum tolerable value since from that moment the germination process is assumed to start. The VTT model is based on regression analysis of a set of measured data. Based on the 
different measurements, the influence of temperature, relative humidity, surface, exposure time and dry periods is included in the VTT model. The model was initially developed for pine and spruce sapwood materials based on lab experiments, and afterwards it was expanded for other building materials [54]. The models define the materials according to four mould sensitivity classes: very sensitive, sensitive, medium resistant and resistant. The sensitivity classes together with the subdivision of the tested materials and an overview of the materials that belong to the different classes are given in Table 3. The VTT mathematical model can be found in details in Viitanen et al. [55].

Table 3: Materials' sensitivity classes [55]

\begin{tabular}{|c|c|c|}
\hline Sensitivity class & Tested materials & Material group \\
\hline Very sensitive & Pine sapwood & Untreated wood: includes lots of nutrients \\
\hline Sensitive & $\begin{array}{l}\text { Glued wooden boards, } \\
\text { Polyurethane with paper } \\
\text { surface, spruce }\end{array}$ & $\begin{array}{l}\text { Planed wood: paper-coated products, } \\
\text { wood-based boards }\end{array}$ \\
\hline Medium resistant & $\begin{array}{l}\text { Concrete, aerated and cellular } \\
\text { concrete, glass wool, polyester } \\
\text { wool }\end{array}$ & $\begin{array}{l}\text { Cement or plastic based materials, mineral } \\
\text { fibers }\end{array}$ \\
\hline Resistant & $\begin{array}{l}\text { Polyurethane with polished } \\
\text { surface }\end{array}$ & $\begin{array}{l}\text { Glass and metal products, materials with } \\
\text { efficient protective compound treatments }\end{array}$ \\
\hline
\end{tabular}

Using the measured temperatures and relative humidity at each position within test walls 1 and 2, the RH85 and the VTT mould growth index "M" are calculated and plotted in Figure 13 and Figure 14 for test walls 1 and 2, respectively. It is worth mentioning that the assessment should be considered for much longer period, but no measurement data long enough are available for such assessment. To calculate the VTT mould growth index (M), the concrete masonry is assumed to lie in the medium resistant class. The VTT model is written in MATLAB ${ }^{\circledR}$ to postprocess the hygrothermal experimental results.

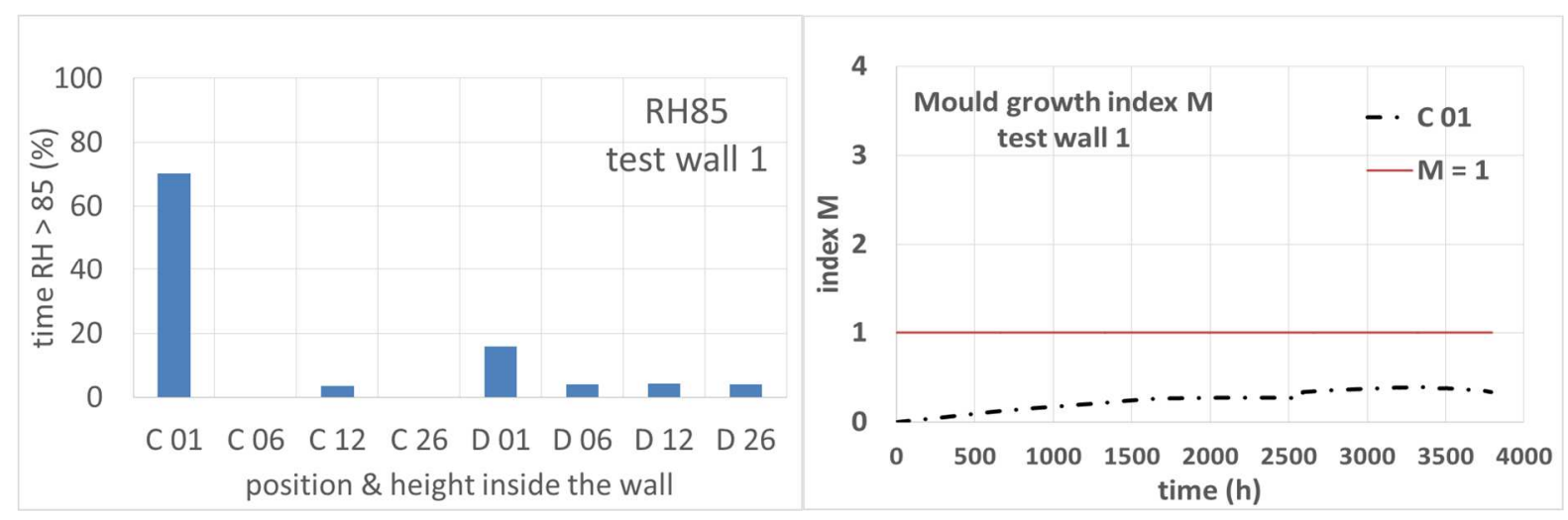

Figure 13: RH85 and mould growth index $M$ for test wall 1 at different positions and heights 

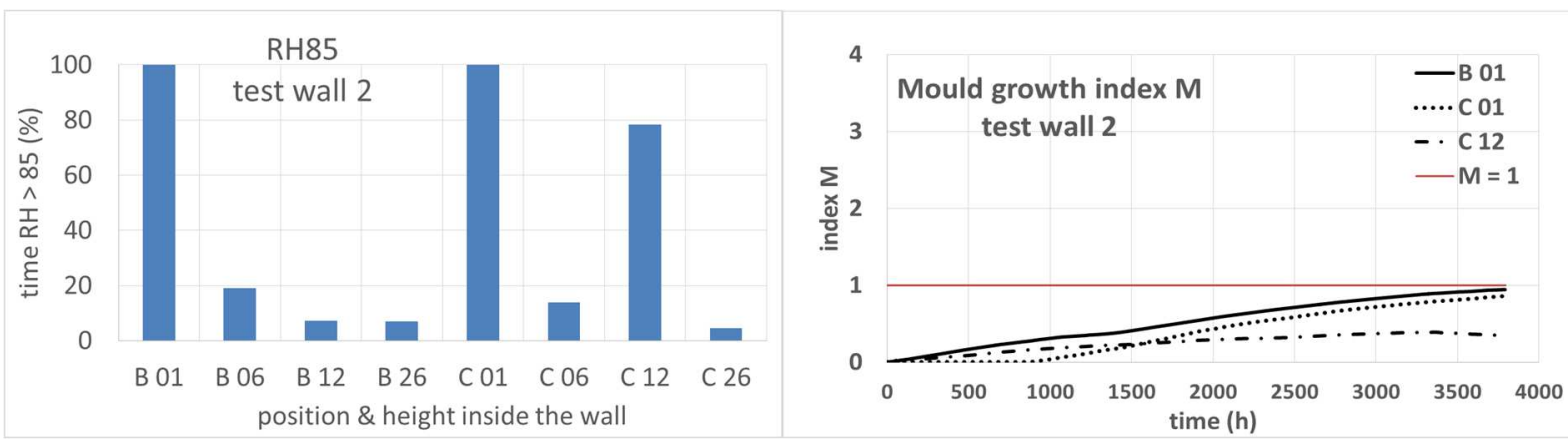

Figure 14: RH85 and mould growth index $M$ for test wall 2 at different positions and heights

A high risk for mould growth are observed at the bottom position near the ground due to the high moisture contents. For test wall 1, low risk for mould growth is observed near the window, most probably due to the presence of the aerogel insulation on the reveal. However, for test wall 2 with no insulation on the window reveal, high humidity level and high risk for mould growth are observed at position $1.2 \mathrm{~m}$ near the window reveal.

3.3. Analysis of the measured surface temperature and heat flux profiles

The exterior surface (so) and the interior surface (si) temperatures of the two test walls are shown in Figure 15. The exterior surface temperature of test wall 1 is higher than that of test wall 2 during day time and is lower during night time. The reason is the presence of a shading element just in front of test wall 2. Therefore, test wall 2 receives lower (diffused) solar radiation during daytime and emits lower long-wave radiation during night time in addition to a lower convention coefficient.

As illustrated in Figure 15, the interior surface temperatures of both test walls remain relatively stable with very low fluctuations, even though the exterior surface show high fluctuations. The interior surface temperature fluctuates of no more than $1.5^{\circ} \mathrm{C}$ between day and night. A time lag is also pronounced between the interior and the exterior surface temperatures. 


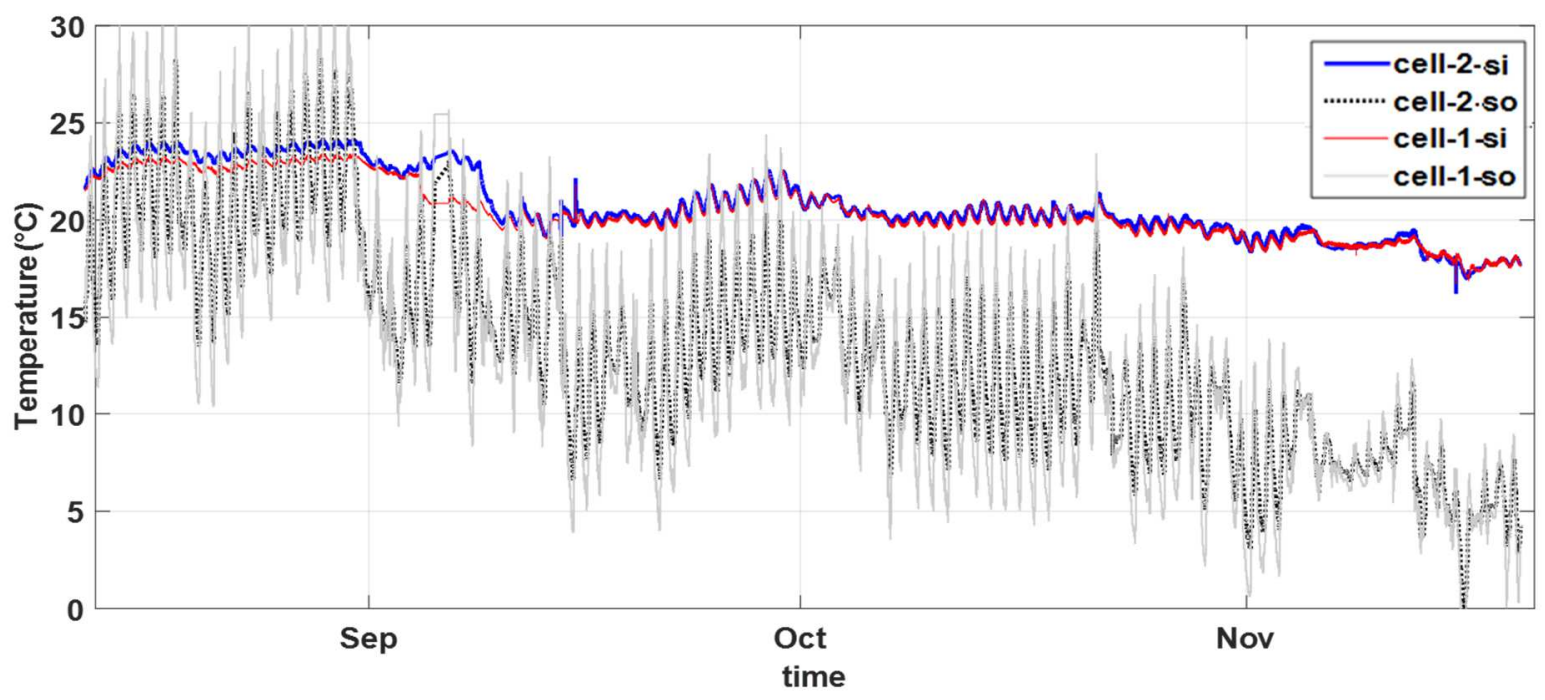

Figure 15: Exterior surface (so) and interior surface (si) temperatures for test walls 1 and 2

The temperature profiles within the cross section of the walls for a selected day in winter are shown in Figure 16 at different hours of the day. As illustrated, a high temperature gradient appears across the aerogel-based insulation due to its high thermal resistance keeping the indoor temperature and the temperature behind the insulation almost constant across the day. A temperature gradient of more than $10^{\circ} \mathrm{C}$ is pronounced. It is also possible to conclude that both solutions permit to have comfort conditions in the two indoor environments.
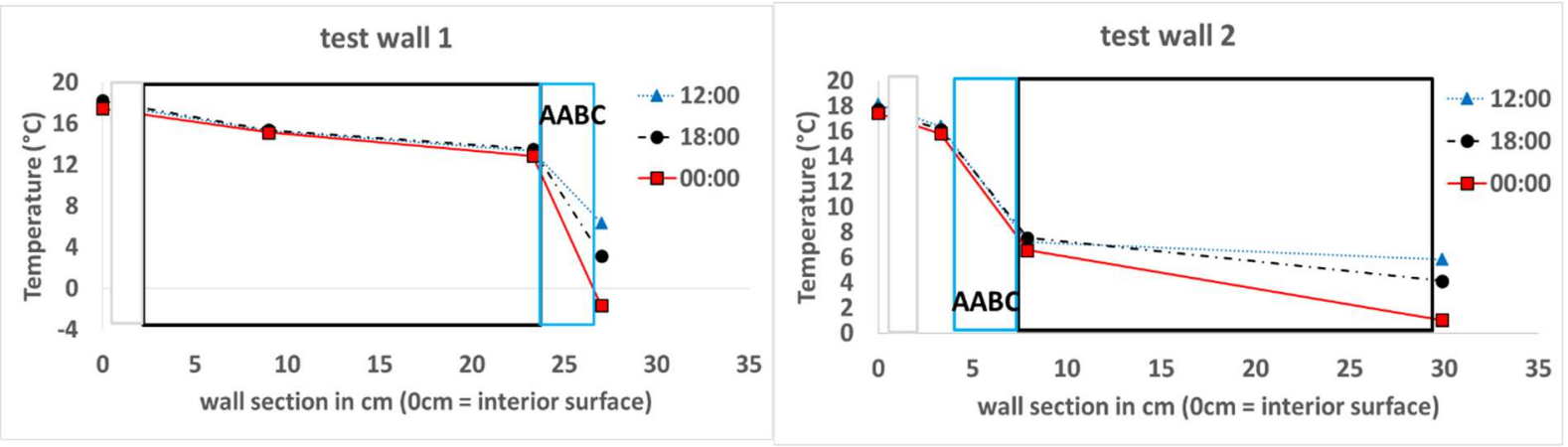

Figure 16: The temperature profiles across the cross section of the walls for a selected day in winter at different hours of the day for test wall 1 (left) and test wall 2 (right).

The daily average heat flux and the daily average temperature difference between the interior and the exterior wall surfaces for both test walls are shown in Figure 17 and Figure 18 for the winter period. As expected, the heat flux increases with the increase in the temperature gradient between indoors and outdoors. The daily average heat flux varies between 6 and 10 $\mathrm{W} /\left(\mathrm{m}^{2} . \mathrm{K}\right)$ for relatively low temperature gradients and between 12 and $16 \mathrm{~W} /\left(\mathrm{m}^{2} . \mathrm{K}\right)$ for relatively higher temperature gradients. 




Figure 17: The daily average heat flux and the daily average temperature difference between the interior and the exterior wall surfaces for test wall 1



Figure 18: The daily average heat flux and the daily average temperature difference between the interior and the exterior wall surfaces for test wall 2

There was no reference test wall without the aerogel-based insulation systems to be able to compare the performance. Therefore, trying to compare the aerogel-based insulated walls with a reference un-insulated wall, and considering the in-situ $\Lambda$-value for the concrete hollow block part of the wall measured and presented previously in section 3.1, we considered a "theoretical" reference wall composed of $20 \mathrm{~cm}$ of concrete hollow block with a $\Lambda$-value equals to $4.0\left(\mathrm{~W} / \mathrm{m}^{2} \mathrm{~K}\right)$. The daily average heat flux crossing the reference wall is calculated as the $\Lambda$-value multiplied by the daily average temperature difference between interior and exterior surfaces.

The daily average heat flux is plotted against the daily average temperature difference for the test walls and for the theoretical reference wall in Figure 19. As illustrated, a linear correlation fits well the measured data for the test walls. As illustrated, the heat flux crossing the insulated walls is highly reduced compared to the reference one. 

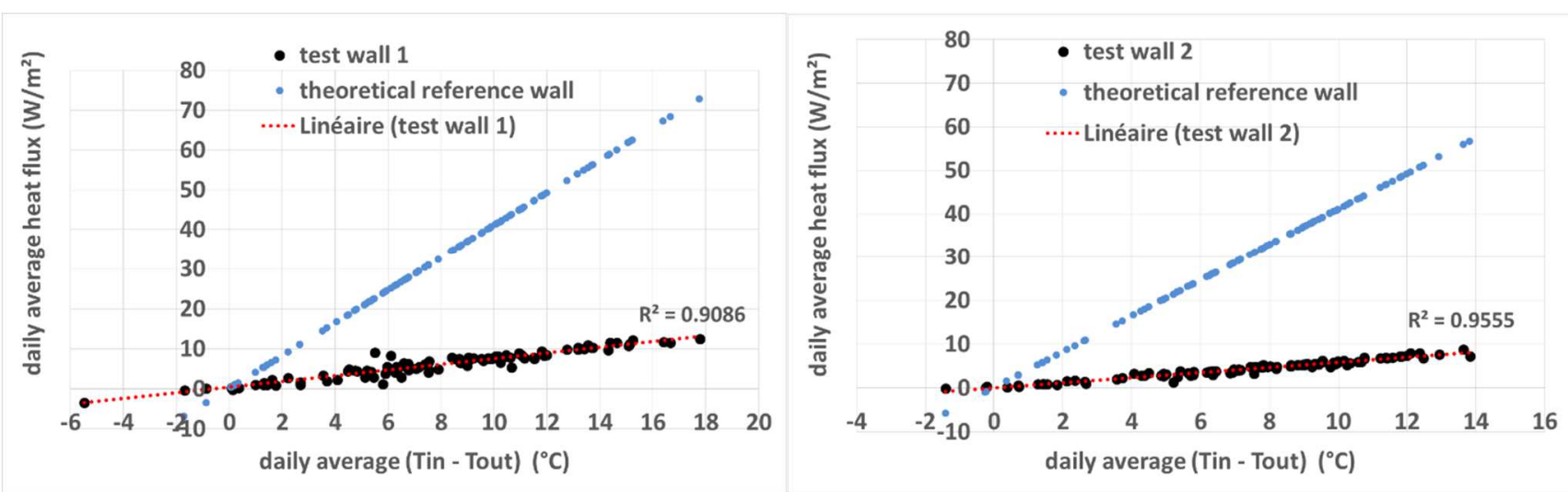

Figure 19: the daily average heat flux versus the daily average temperature difference for the test walls and the theoretical reference wall

4. Hygrothermal numerical models' validation

\subsection{The numerical models}

The one-dimensional hygrothermal numerical models in transient condition of the two test walls have been developed by means of the software WUFI ${ }^{\circledR}$ Pro 5.3 [39], which considers coupled heat and moisture transfer through the assembly and complies with standard EN 15026 [56]. The governing equations for heat and moisture transport are given in Eqs. (3), (4), respectively.

$$
\begin{gathered}
\frac{\partial H}{\partial T} \frac{\partial T}{\partial t}=\nabla(k \nabla T)+h_{v} \nabla\left(\delta_{p} \nabla\left(\varphi P_{s a t}\right)\right) \\
\frac{\partial w}{\partial \varphi} \frac{\partial \varphi}{\partial t}=\nabla\left(D_{\varphi} \nabla \varphi+\delta_{p} \nabla\left(\varphi P_{s a t}\right)\right)
\end{gathered}
$$

where $H, T, w$ and $\varphi$ are enthalpy, temperature, moisture content, and relative humidity, respectively. $P_{\text {sat, }} k, h_{v}, \delta_{p}$ and $D_{\varphi}$ are the saturation pressure, thermal conductivity, evaporation enthalpy of water, water vapor permeability, and liquid conduction coefficient, respectively.

For the numerical solution, $\mathrm{WUFI}^{\circledR}$ uses the finite volume technique for the spatial discretization of the transport equations and uses the fully implicit scheme for the discretization in time. The solver computes the temperature and relative humidity profiles of the next time step by iterating the heat and mass balance equations until convergence Is reached.

The model for test wall 1 (exterior insulation) is shown in Figure 20 and that for test wall 2 (interior insulation) is shown in Figure 21. 


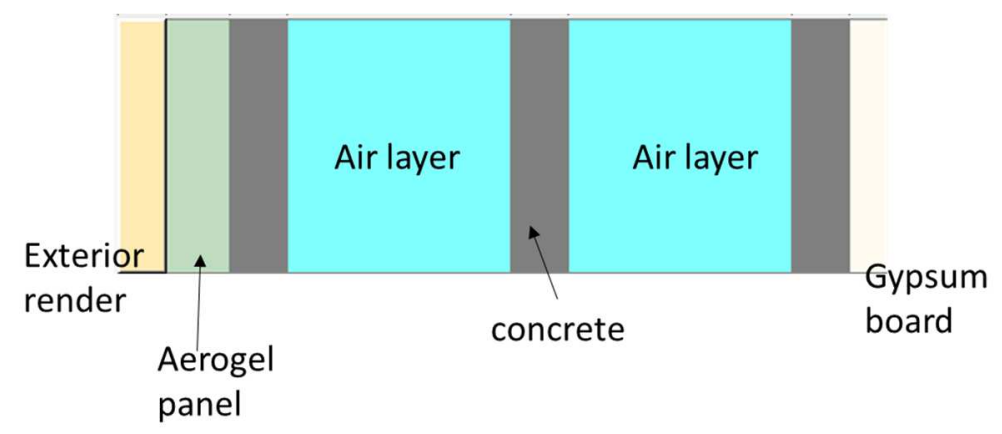

Figure 20: numerical model wall layers - test wall 1

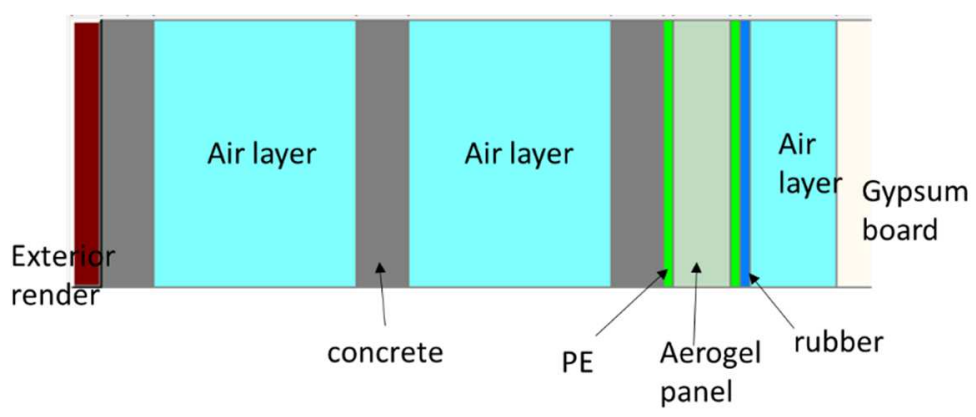

Figure 21: numerical model wall layers - test wall 2 ( $P E=$ Polyethylene)

The material properties of the single layers composing the wall, except the aerogel-panel, the polyethylene layer, and the synthetic rubber, are not directly measured, so they were selected from the materials database. The concrete block is modelled as shown in the figures as a 5 layers component: concrete / air gap / concrete / air gap / concrete. It is to be noted that for test wall 2 , the numerical model reflects the same layer configuration as the constructed façade shown previously in Figure 3; however, for test wall 1, the exterior layers (basecoat, mesh, primer, and finishing) are all regrouped in one single layer, the exterior render, whose properties are to be calibrated. The reason is to simplify the modelling process and to reduce the number of variables to calibrate. Initially, the air gap thermal conductivity from the WUFI database is $0.59 \mathrm{~W} /(\mathrm{m} . \mathrm{K})$ for a $100 \mathrm{~mm}$ thickness; however, this value was set as a variable value in our calibration procedure as to account for the thermal bridges generated by the concrete connections within the concrete block itself. This is more explained in the following section. The exterior and interior environmental conditions (temperature, solar radiation, rain, etc.) are constructed from the experimental measurements of the on-site weather station and from the indoor hygrothermal sensors. The exterior boundary conditions and the interior boundary conditions for the both test cells are shown in Figure 22. 



Figure 22: Exterior boundary conditions (top) and Interior boundary conditions (Temperature and relative humidity) for test cell 1 and test cell 2 (bottom)

\subsection{Model calibration}

Due to several sources of uncertainties, a calibration procedure is necessary to have the hygrothermal model results approach those of the experimental measurements. The calibration procedure is summarised in the following steps:

1- A first model was constructed for the each of the two test walls using the available measured data for the aerogel panel, for PE, and for the rubber layers, and using materials data from the WUFI database for the other layers.

2- Using the measured in-situ $\Lambda$-values for the $A A B C$ systems and for the concrete wall structure, the thermal conductivity of the aerogel-panel and that of the air-layer are adjusted to the corresponding $\Lambda$-value. 
3- A parametric analysis is carried out varying different parameter values (increasing/decreasing by a certain percentage) to reach a better fit and to determine the most influential parameters that affects this experiment/simulation calibration.

4- The methodology followed is to calibrate the temperature field before calibrating the humidity field, as the parametric analysis showed that the humidity-related parameters do not affect sensitively the temperature fit.

5- The parameters that are altered include, but are not limited to,

- $\quad$ The air layer thermal conductivity

- The initial water content of the wall assembly

- The PE vapour diffusion resistance factor

- The PE thickness

- The synthetic rubber vapour diffusion resistance factor

- The synthetic rubber thickness

- The exterior render vapour diffusion resistance factor

- The exterior surface solar absorptivity

- The exterior surface thermal emissivity

- The exterior surface convective heat transfer coefficient (constant or wind dependant)

- The interior surface heat transfer coefficient

- The aerogel panel thermal conductivity

- The rain adhering coefficient

- The concrete's vapour diffusion resistance factor

The models are calibrated for a position behind the $A A B C$ system, i.e. the interface $\mathrm{AABC} /$ concrete block in both test walls.

\subsection{Model validation results}

\subsubsection{Test wall 1 (1-dimensional)}

Using this parametric analysis, we identified several parameters that affect the model fitting into the monitored data. The first parameter is the initial water content of the assembly which has a great influence on the results. Since the moisture transfer is relatively slow, we usually need several months (or even years) to overcome the effect of the initial conditions of the wall structure. Therefore, different values for the initial water content of the whole assembly are tested. 
Another parameter that is identified as very influential is the thermal conductivity of the air layers (air holes) inside the concrete block. We started with the value in the materials database of $0.5 \mathrm{~W} /(\mathrm{m} . \mathrm{K})$. This value was then increased due to the fact that the concrete joints inside the concrete hollow block itself create thermal bridges.

As a result, the best combination occurs when the initial relative humidity inside the assembly is $72 \%$ and the thermal conductivity of the air layer is $0.7 \mathrm{~W} /(\mathrm{m} . \mathrm{K})$. In general, this initial relative humidity is realistic for a newly built wall. The wall was built some weeks before the start of the measurement campaign. This can explain why higher initial $\mathrm{RH}$ values were not the best ones for an optimal fit.

As for the thermal conductivity of the air holes which is found optimal at $0.7 \mathrm{~W} /(\mathrm{m} . \mathrm{K})$, with such a value, the thermal conductance of the concrete block is $4.34 \mathrm{~W} /\left(\mathrm{m}^{2} \mathrm{~K}\right)$ which is very close to that of the in-situ measured one presented previously $4.10 \mathrm{~W} /\left(\mathrm{m}^{2} \mathrm{~K}\right)$.

For the short-wave solar absorptivity of the exterior surface, a range of values between 0.05 and 0.3 has been considered, because of the properties of the (newly applied) exterior finishing which has a white colour with a value of 0.22 measured at lab-scale. A value of 0.1 is found optimum.

The external surface heat resistance has been considered as wind-dependant and as a constant. We tried $0.04 \mathrm{~m}^{2}$.K/W (from EN ISO 6946), 0.0588 $\mathrm{m}^{2} \mathrm{~K} / \mathrm{W}$ (from WUFI predefined value for external wall), $0.0833 \mathrm{~m} 2 . \mathrm{K} / \mathrm{W}$ (user defined) and $0.071 \mathrm{~m} 2 . \mathrm{K} / \mathrm{W}$ (user defined). The best results are obtained for a heat resistance of $0.071 \mathrm{~m}^{2} . \mathrm{K} / \mathrm{W}$. The simulations without wind effects are slightly better than those with the wind effect.

The long-wave radiation heat transfer coefficient is modelled as a constant value (equals to $6.5 \mathrm{~W} /\left(\mathrm{m}^{2} \mathrm{~K}\right)$ ) and using an explicit radiation balance using the counter-radiation data (on a horizontal surface) provided by the weather station and included in the constructed weather file. A better fit is observed for the explicit radiation method. The outside ground solar reflectance has no significant effect on the results.

The interior surface heat transfer coefficient (combined convective and radiative) is varied between $2 \mathrm{~W} /\left(\mathrm{m}^{2} \mathrm{~K}\right)$ and $14 \mathrm{~W} /\left(\mathrm{m}^{2} \mathrm{~K}\right)$ with an increment of $2 \mathrm{~W} /\left(\mathrm{m}^{2} \mathrm{~K}\right)$, and the best fit is observed for $8 \mathrm{~W} /\left(\mathrm{m}^{2} \mathrm{~K}\right)$. This value is close to that recommended in several literature $\left(3-4 \mathrm{~W} /\left(\mathrm{m}^{2} . \mathrm{K}\right)\right.$ for convective part and $4.5 \mathrm{~W} /\left(\mathrm{m}^{2} . \mathrm{K}\right)$ for radiative part).

The parameter of normal rain, converted into the driving rain load on the surface, has been changed in terms of adhering factor, considering also the no rain absorption case. As a result the rain load adhering factor, from 0 (no absorption) to 1 (maximum value), does not affect sensitively the results. It is due to the presence of water repellent finishing as external layer with very low water absorption coefficient. 
Table 4 summarizes the parametric analysis that was carried out. Since the hygrothermal parameters are correlative, a lot of different combinations of the various parameters were simulated. (it is to be noted that not all combinations were simulated due to the very large number of simulations needed). As mentioned earlier, the calibration was done step by step. Firstly, the temperature filed is calibrated by changing the different parameters. When a certain parameter is identified is low-influential, its value is fixed and becomes not part of the parametric analysis. Secondly, the moisture field is calibrated reaching the optimal fit for both temperature and relative humidity.

Table 4: the variables used in the parametric analysis

\section{Parameter}

Air hole thermal conductivity [W/(m.K)]

Exterior render water absorption coefficient

$\left[\mathrm{kg} /\left(\mathrm{m}^{2} \cdot \mathrm{h}^{0.5}\right)\right]$

Exterior render water vapour diffusion

resistance factor

Rain adhering coefficient

Exterior heat transfer coefficient $\left[\mathrm{W} /\left(\mathrm{m}^{2} . \mathrm{K}\right)\right]$

Radiative part of the exterior heat transfer

coefficient $\left[\mathrm{W} /\left(\mathrm{m}^{2} \cdot \mathrm{K}\right)\right]$

Inside heat transfer coefficient $\left[\mathrm{W} /\left(\mathrm{m}^{2} . \mathrm{K}\right)\right]$

Exterior surface solar absorptivity [-]

Initial relative humidity [\%]

\section{Value}

$0.4,0.52,0.7,0.8,0.9$

$0.1,0.2,0.3,1$

$10,20,30$

$0,0.3,0.7,1$

$12,14,17,25$, wind dependant

6.5 , explicit radiation balance

$2,4,8,12,14$

$0.05,0.1,0.2,0.3$

$85,80,75,72,70,60,50$

We used the boxplot as a statistical method to assess the agreement between simulation results and measured values. As an example, the boxplot for few selected cases is shown in Figure 23 and Figure 24. 


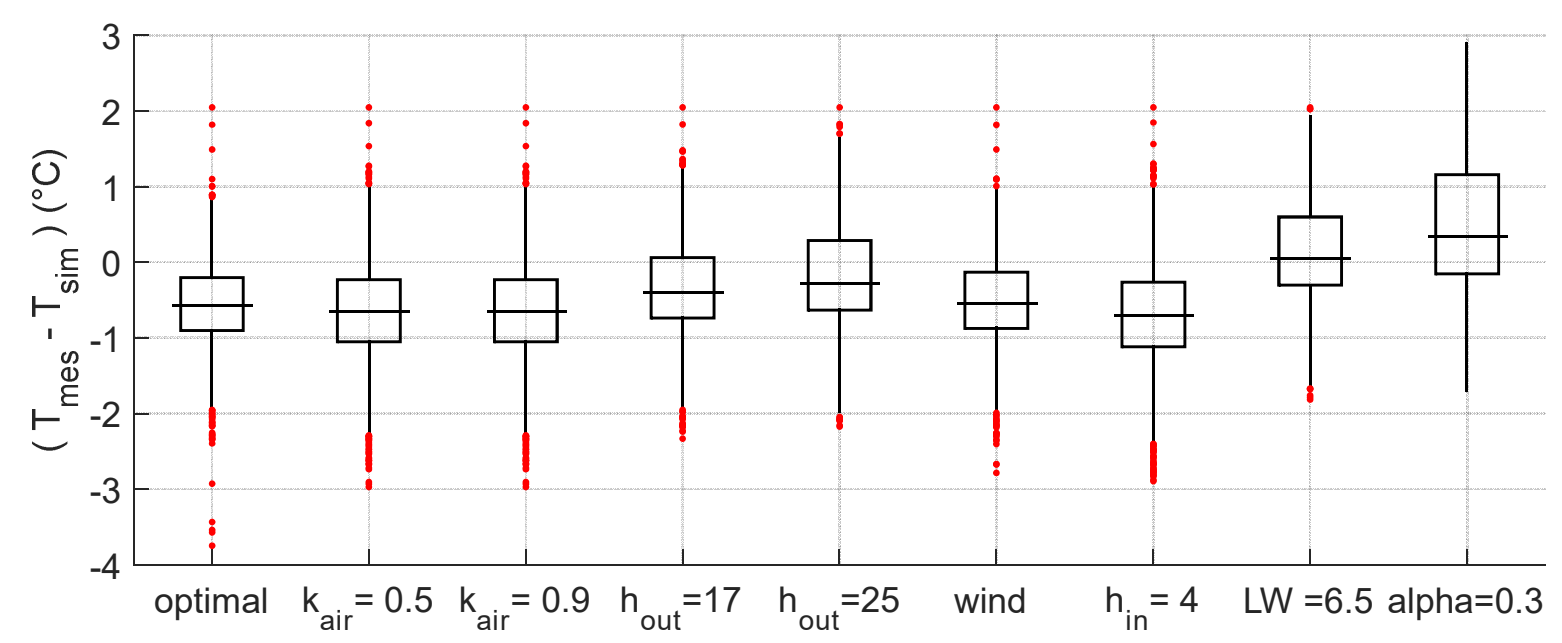

Figure 23: box plot for the difference between measured and simulated temperatures for few selected cases (test wall 1); (k: thermal conductivity; $h_{\text {out }}$ : outside heat transfer coefficient; $h_{\text {in: }}$ : inside heat transfer coefficient; wind: wind dependant heat transfer coefficient; LW: long wave radiation heat transfer coefficient; alpha: solar absorptivity)

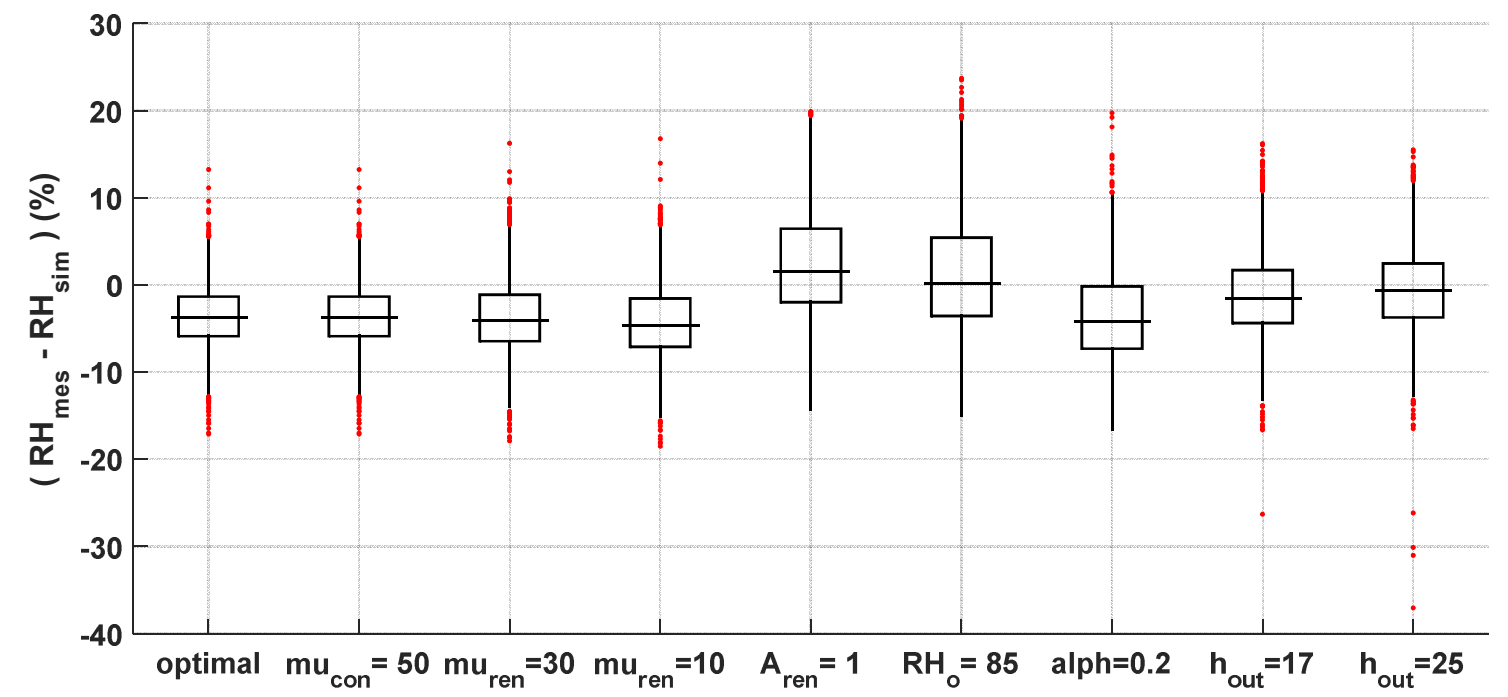

Figure 24: box plot for the difference between measured and simulated relative humidity for few selected cases (test wall 1); (mu: water vapour diffusion resistance factor; con: concrete; ren: outside render; $\mathrm{A}$ : water absorption coefficient; $\mathrm{RH}_{0}$ : initial relative humidity)

For the optimum model, the simulated and measured temperature and relative humidity at the interface $A A B C /$ concrete block are shown in Figure 25 and Figure 26, respectively. The wall materials hygrothermal properties are listed in Table 5. 




Figure 25: simulation and experiment temperature agreement - test wall 1

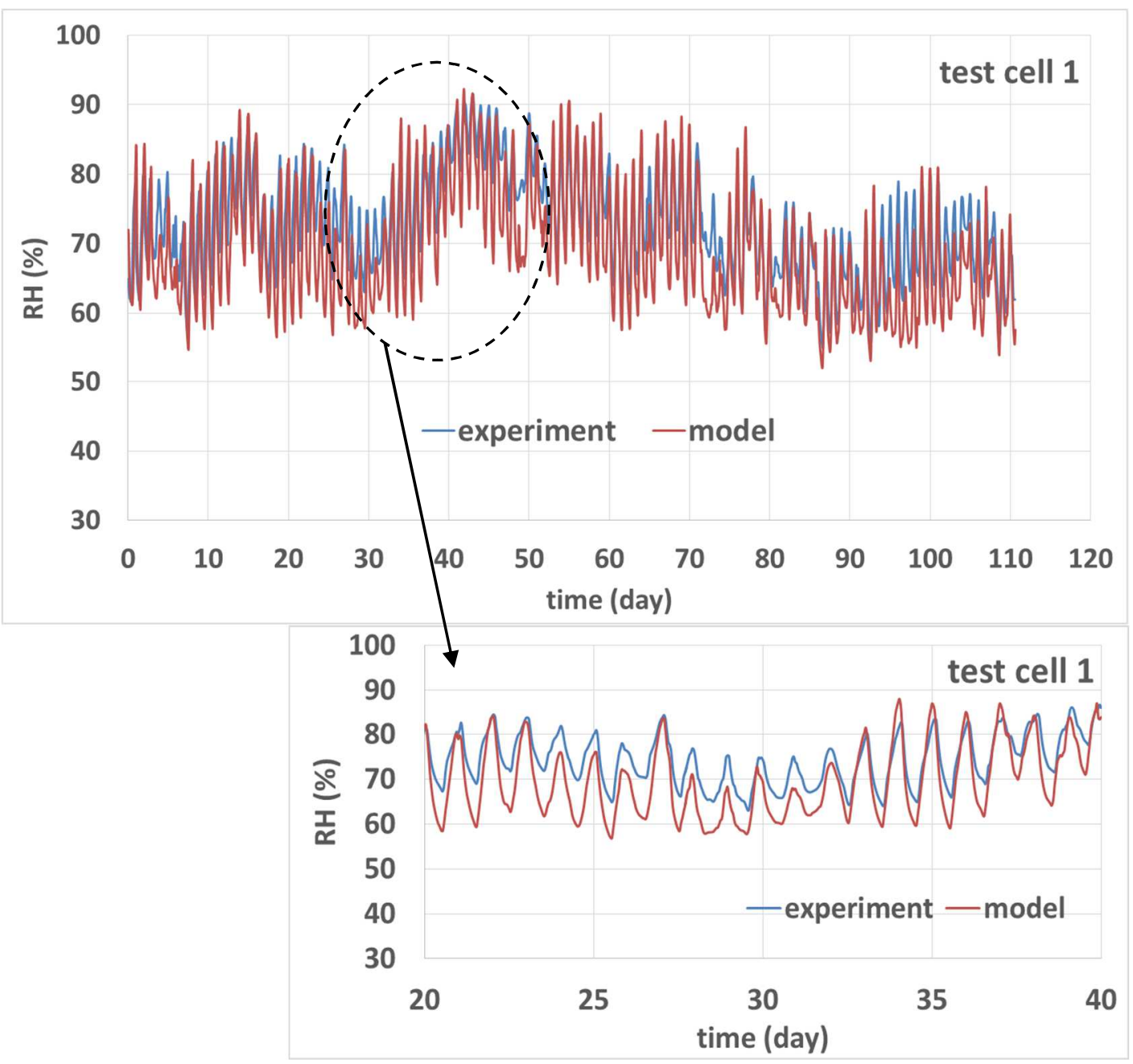

Figure 26: simulation and experiment relative humidity agreement - test wall 1 
Table 5: test-wall-1 materials hygrothermal properties

\begin{tabular}{|c|c|c|c|c|c|}
\hline Material & $\begin{array}{c}\text { Thickness } \\
{[\mathrm{cm}]}\end{array}$ & $\begin{array}{c}\text { Thermal } \\
\text { conductivity } \\
{[\mathrm{W} /(\mathrm{m} . \mathrm{K})]}\end{array}$ & $\begin{array}{c}\text { Specific heat } \\
{[\mathrm{J} /(\mathrm{kg} . \mathrm{K})]}\end{array}$ & $\begin{array}{c}\text { density } \\
{\left[\mathrm{kg} / \mathrm{m}^{3}\right]}\end{array}$ & $\begin{array}{c}\text { Water vapour } \\
\text { diffusion resistance } \\
\text { factor }[-]\end{array}$ \\
\hline $\begin{array}{c}\text { Exterior } \\
\text { render }\end{array}$ & 1.3 & 0.8 & 1500 & 1900 & 60 \\
\hline $\begin{array}{c}\text { Aerogel- } \\
\text { based } \\
\text { blanket }\end{array}$ & 2 & 0.0171 & 780 & 180 & $\begin{array}{c}5 \text { (wet) } \\
8 \text { (dry) }\end{array}$ \\
\hline Concrete & 1.8 & 4.34 & 850 & 2000 & 100 \\
\hline Air layer & 7 & 0.70 & 1000 & 1.3 & 0.73 \\
\hline $\begin{array}{c}\text { Gypsum } \\
\text { board }\end{array}$ & 1.3 & 0.2 & 850 & 850 & 8.3 \\
\hline
\end{tabular}

As illustrated, the simulated temperature field is very close to that of measurements and lies within the uncertainty of the measurement sensors. In addition, the daily dynamics are also captured by the numerical model. For example, at day '43', a large step (jump) in the measured temperature is observed from $19^{\circ} \mathrm{C}$ to around $25^{\circ} \mathrm{C}$ which is very well captured by the numerical model. For the relative humidity, lower agreement is obtained compared to the temperature field. The model is capable of reproducing values close to those of the experiment, but more daily fluctuations are observed in the numerical model.

To quantify the agreement between simulation and measurement, some statistical parameters are calculated which are defined as:

- The percentage root mean square error (PRMSE), which is defined as

$$
\text { PRMSE }=\sqrt{\frac{1}{n} \sum_{i=1}^{n}\left(\frac{Y s_{i}-Y m_{i}}{Y m_{i}}\right)^{2}} * 100
$$

where $n$ is the total number of measurements over a certain period and $Y s_{i}$ and $Y m_{i}$ are the simulated and the measured values (temperature or relative humidity), respectively.

- The root mean square error (RMSE), which is calculated as following

$$
R M S E=\sqrt{\frac{1}{n} \sum_{i=1}^{n}\left(Y s_{i}-Y m_{i}\right)^{2}}
$$

- The average value of the absolute difference between the simulated and the measured values, together with its standard deviation

$$
|\bar{\Delta}|=\frac{1}{n} \sum_{i=1}^{n}\left|Y s_{i}-Y m_{i}\right|
$$




$$
\sigma_{|\bar{\Delta}|}=\sqrt{\frac{1}{n} \sum_{i=1}^{n}\left(|\Delta|_{i}-|\bar{\Delta}|\right)^{2}}, \text { with }|\Delta|_{i}=\left|Y s_{i}-Y m_{i}\right|
$$

The PRMSE and RSME testify the good agreement between the simulated values and the measured data. As shown in Table 6, the PRMSE of the temperature and relative humidity is around $3.98 \%$ and $6.20 \%$, respectively. The average difference between the measured and the simulated values is around $0.65^{\circ} \mathrm{C}$ for temperature with a standard deviation of around $0.42^{\circ} \mathrm{C}$, and is around $5.26 \%$ for relative humidity with a standard deviation of around $2.66 \%$.

Table 6: The performance indicators to assess the simulation results agreement with the experimental data

$$
\begin{array}{ccccc} 
& \text { PRMSE } & \text { RMSE } & |\bar{\Delta}| & \sigma_{|\bar{\Delta}|} \\
& & & & \\
\text { T } & 3.98 \% & 0.78^{\circ} \mathrm{C} & 0.65^{\circ} \mathrm{C} & 0.42^{\circ} \mathrm{C} \\
& & & & \\
\text { RH } & 6.20 \% & 8.56 \% & 5.26 \% & 2.66 \%
\end{array}
$$

In addition, the simulated temperatures are plotted against the measured temperatures in Figure 27 (left) and the simulated relative humidity is plotted against the measured relative humidity in Figure 27 (right). As shown a very good agreement is obtained for the optimal numerical model.
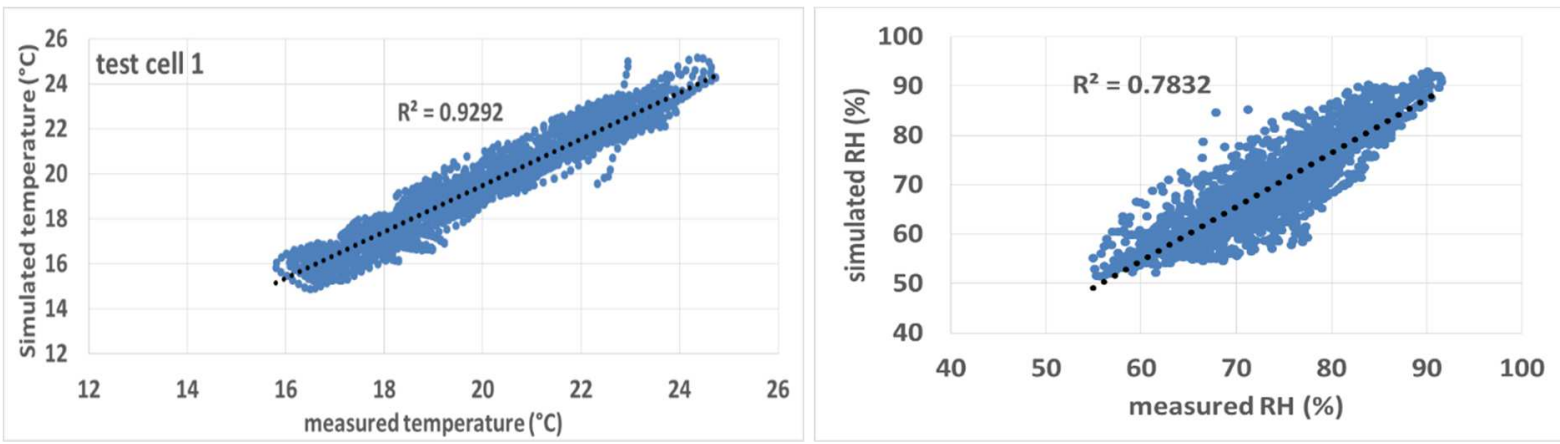

Figure 27: simulation vs measured values for temperatures (left) and relative humidity (right)

\subsubsection{Test wall 2 (1-dimensional)}

The parametric analysis methodology is repeated for test wall 2. In terms of the most influential parameters on the model calibration, the test wall 2 behaves similarly to test wall 1 , but with some few differences. It is worth mentioning that some materials' hygrothermal properties were measured at lab-scale [30], [31] and were used as initial values for the calibration procedures. The calibration results are better when the thermal conductivity of the air holes of the concrete block is $0.6 \mathrm{~W} /(\mathrm{m} . \mathrm{K})$ which is a little bit lower than that of test wall 1.

Concerning relative humidity, in addition to the initial conditions, the water vapour diffusion resistance factor of the synthetic rubber has a very significant influence on the results. By 
changing this value, and to have acceptable results, the factor should be reduced by 3.3 times its initial value obtained from lab-scale measurements, from 10000 to 3000 . This may seem unrealistic, therefore, there are two possible reasons for this: either there is a lot of moisture bridges in addition to air flows due to infiltrations/exfiltration or (and) the material should be represented by smaller thickness. The latter alternative is reasonable due to irregularity of thickness of the material itself and/or at the installation site.

In addition, a better fit is observed with a water vapour diffusion resistance factor of the concrete layer of 100. In addition, the exterior render's vapour diffusion resistance and liquid capillarity coefficient have some influence on the results. The thermal conductivity of the air holes appeared also to have a very significant influence on the model calibration.

For the optimum model, the simulated and measured temperature and relative humidity at the interface $\mathrm{AABC} /$ concrete block are shown in Figure 28 and the wall materials hygrothermal properties are listed in Table 7.

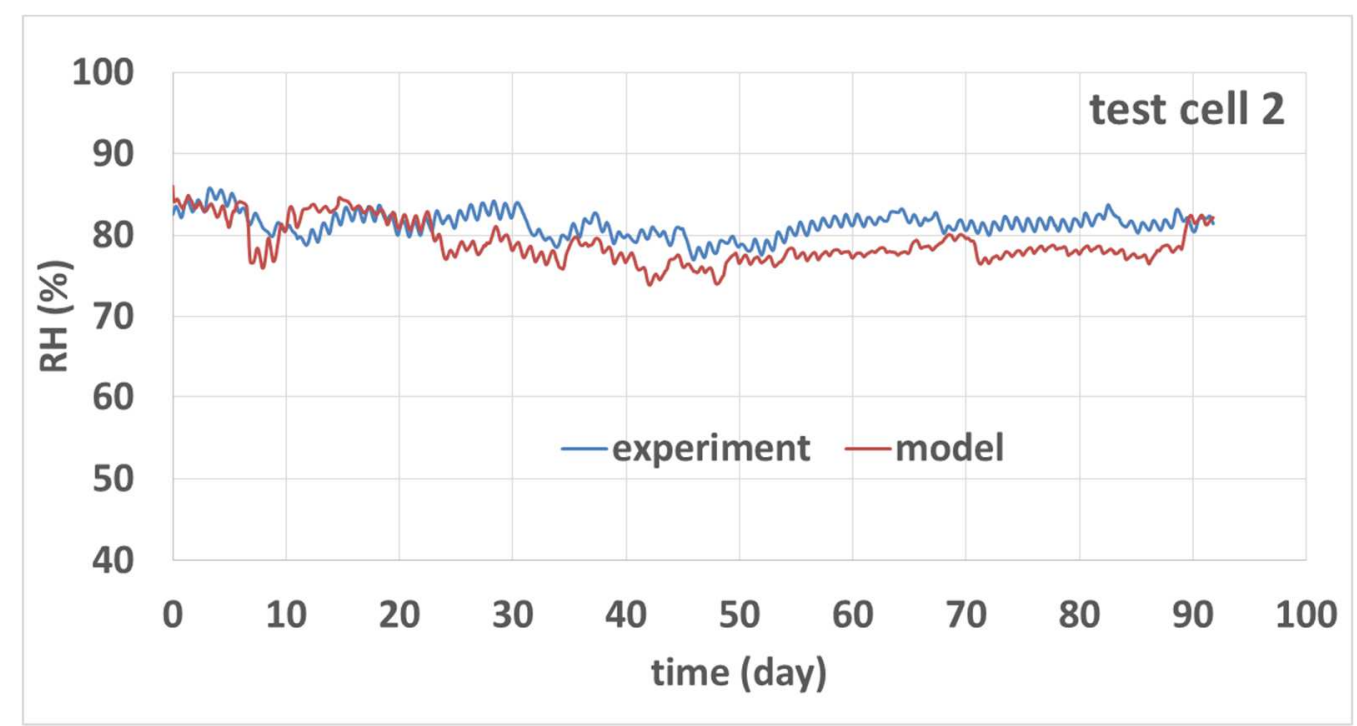

Figure 28: simulation and experiment relative humidity agreement - test wall 2

Table 7: test-wall-2 materials hygrothermal properties

\begin{tabular}{|c|c|c|c|c|c|}
\hline Material & $\begin{array}{c}\text { Thickness } \\
{[\mathrm{cm}]}\end{array}$ & $\begin{array}{c}\text { Thermal } \\
\text { conductivity } \\
{[\mathrm{W} /(\mathrm{m} . \mathrm{K})]}\end{array}$ & $\begin{array}{c}\text { Specific heat } \\
{[\mathrm{J} /(\mathrm{kg} . \mathrm{K})]}\end{array}$ & $\begin{array}{c}\text { density } \\
{\left[\mathrm{kg} / \mathrm{m}^{3}\right]}\end{array}$ & $\begin{array}{c}\text { Water vapour } \\
\text { diffusion resistance } \\
\text { factor [-] }\end{array}$ \\
\hline $\begin{array}{c}\text { Exterior } \\
\text { render }\end{array}$ & 1 & 1.2 & 850 & 2000 & 25 \\
\hline $\begin{array}{c}\text { Aerogel- } \\
\text { based } \\
\text { blanket }\end{array}$ & 2 & 0.0179 & 780 & 180 & 5 (dry) \\
8 (wet)
\end{tabular}


The boxplot for some selected cases is shown in Figure 29

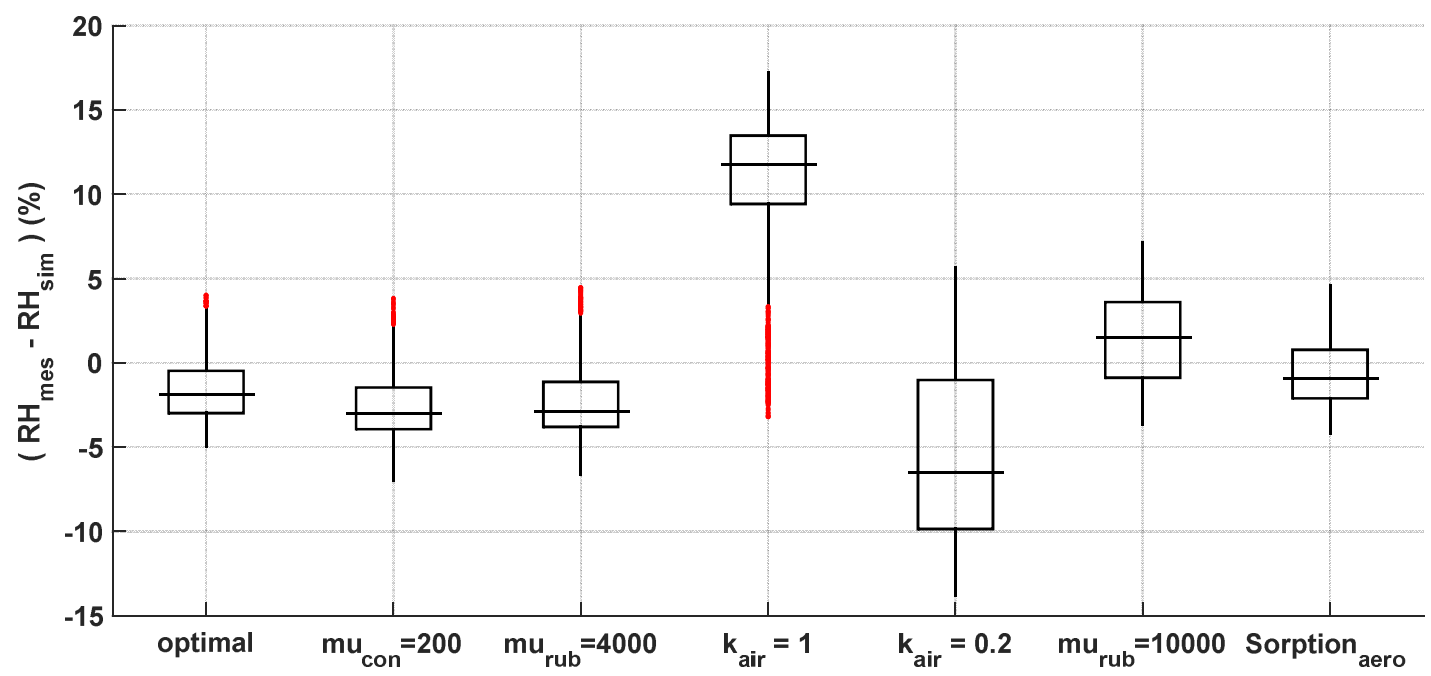

Figure 29: box plot for some selected cases - test wall 2 (sorption: we increased the values in the moisture storage (sorption curve) for the aerogel insulation)

As shown in Table 5, the PRMSE of the temperature and relative humidity is around $3.23 \%$ and $5.10 \%$, respectively. The average difference between the measured and the simulated values $(|\bar{\Delta}|)$ is around $0.55^{\circ} \mathrm{C}$ for temperature with a standard deviation of around $0.39^{\circ} \mathrm{C}$, and is around $3.67 \%$ for relative humidity with a standard deviation of around $1.87 \%$.

Table 8: The performance indicators to assess the simulation values agreement with the experimental data

$\begin{array}{ccccc} & \text { PRMSE } & \text { RMSE } & |\bar{\Delta}| & \sigma_{|\bar{\Delta}|} \\ & & & & \\ T & 3.23 \% & 0.71^{\circ} \mathrm{C} & 0.55^{\circ} \mathrm{C} & 0.39^{\circ} \mathrm{C} \\ & & & & \\ \text { RH } & 5.10 \% & 6.34 \% & 3.67 \% & 1.87 \%\end{array}$

\subsubsection{Test wall 1 (2-dimensional)}

In test wall 1, a layer of $7 \mathrm{~mm}$ thickness of the aerogel panel was applied on all the window reveals to reduce the heat losses of this thermal bridge which is a common thermal bridge for externally insulated walls. After calibrating the 1D heat and moisture model for test wall 1 , it was not very difficult to calibrate the $2 \mathrm{D}$ heat and moisture model. The model is developed using WUFI 2D. As WUFI 1D, WUFI 2D uses the same equations and assumptions to solve the coupled heat and moisture but in a two-dimensional domain. A fine mesh is chosen to increase accuracy. In this case, the calibration is done by varying the vapour diffusion resistance factor and/or thickness of the exterior render and those of the aerogel-panel. The optimal results are obtained for values close to those found for the 1D calibration case. 
The relative humidity and temperature for the position $1.2 \mathrm{~m}$ near the window reveal behind the aerogel insulation are shown in Figure 30 and the agreement between the measured and the simulated data is shown Figure 31. As shown in these figures, a good agreement is obtained. The numerical model will then be used to examine the impact of removing this $7 \mathrm{~mm}$ aerogel layer on the heat loss and on the moisture performance for positions near the window.

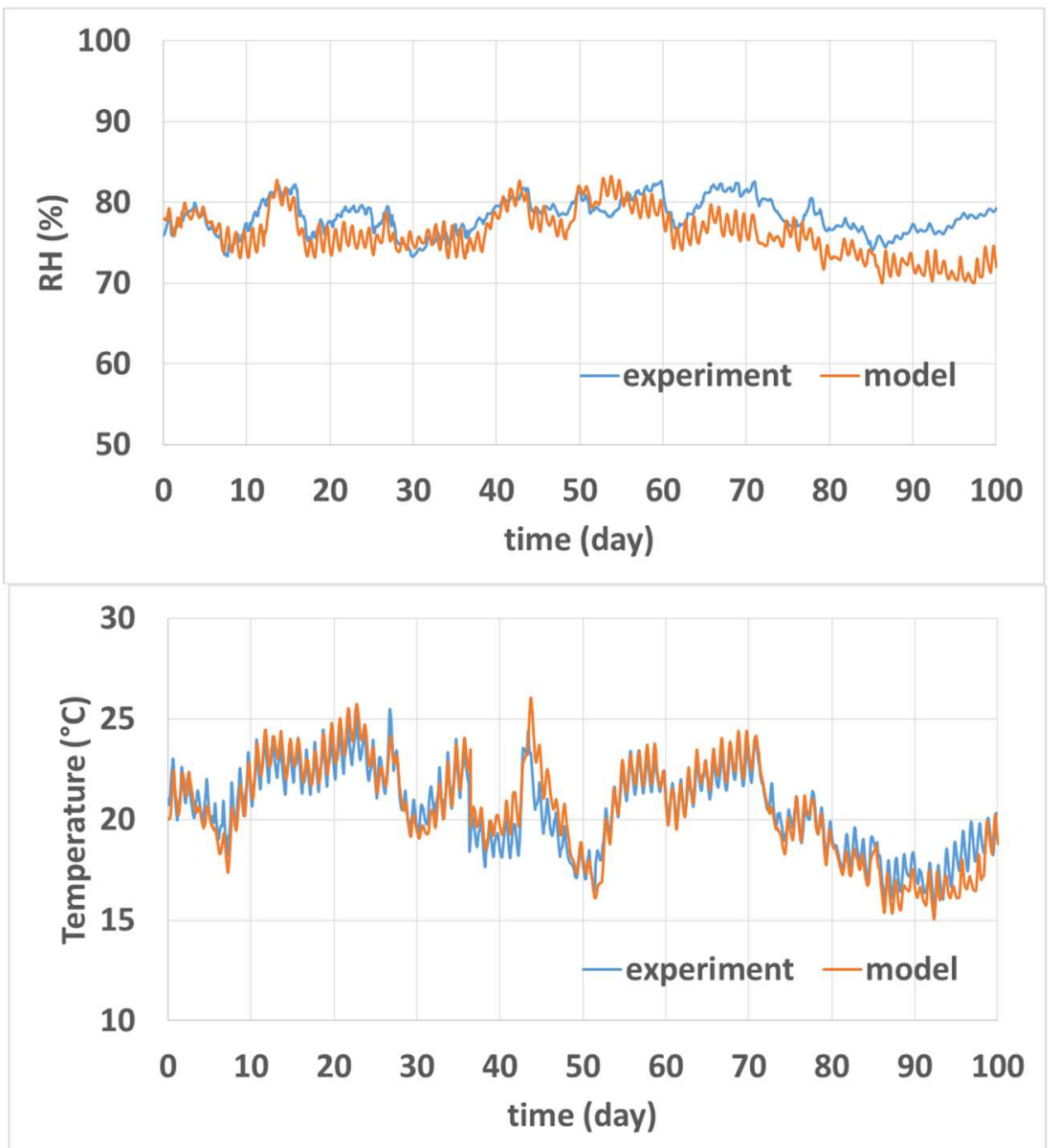

Figure 30: Measured and simulated temperatures (top) and relative humidity (bottom) at position $D$ at the $1.2 \mathrm{~m}$ height
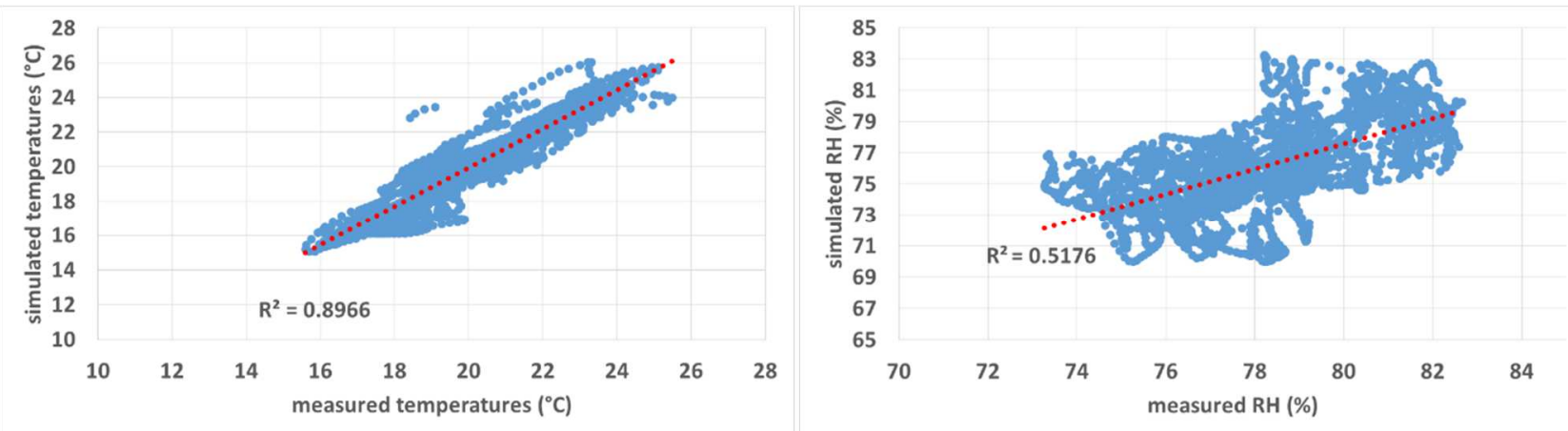

Figure 31: Agreement between the simulated and the measured temperatures (left) and relative humidity (right) at position $D$ at the $1.2 \mathrm{~m}$ height

5. Numerical simulations 


\subsection{1-dimensional case}

The objective is to examine the thermal and moisture performance of the concrete block wall retrofitted with the interior $A A B C$ system using the calibrated numerical model for a selected case study. The objective is also to compare the results of the calibrated model with those of a model where the lab-scale measured values for all the layers are used. In this case study, the internally insulated wall is considered as it is assessed to be more critical in terms of high humidity and mould growth risks.

The climate of the city of Torino (Italy) is chosen as the outside boundary condition for the simulations. The weather file provided in WUFI is used, which represents a test reference year representing typical weather situations. The weather test year is constructed based on 30 years mean values. Using the climate analysis tool provided by $\mathrm{WUFI}^{\circledR}$, a north-west orientation is selected, as it is assessed to be most critical in terms of rain loads and low solar radiation.

The indoor conditions are determined in relation to the exterior climate according to the European standard DIN EN 15026 (2007). The indoor moisture load is considered as "Normal". The outside solar absorptivity is taken as 0.5 . The outside convective heat transfer coefficient is wind dependent. The inside heat transfer coefficient is taken as $8 \mathrm{~W} /\left(\mathrm{m}^{2} . \mathrm{K}\right)$. The building is considered as a single-family detached house (short building). The simulation starts in October for a period of 5 years. The initial relative humidity is considered as $80 \%$ across the wall assembly. The exterior and interior boundary conditions are shown in Figure 32 and Figure 33, respectively.



Figure 32: The exterior air temperature and relative humidity for the city of Torino 


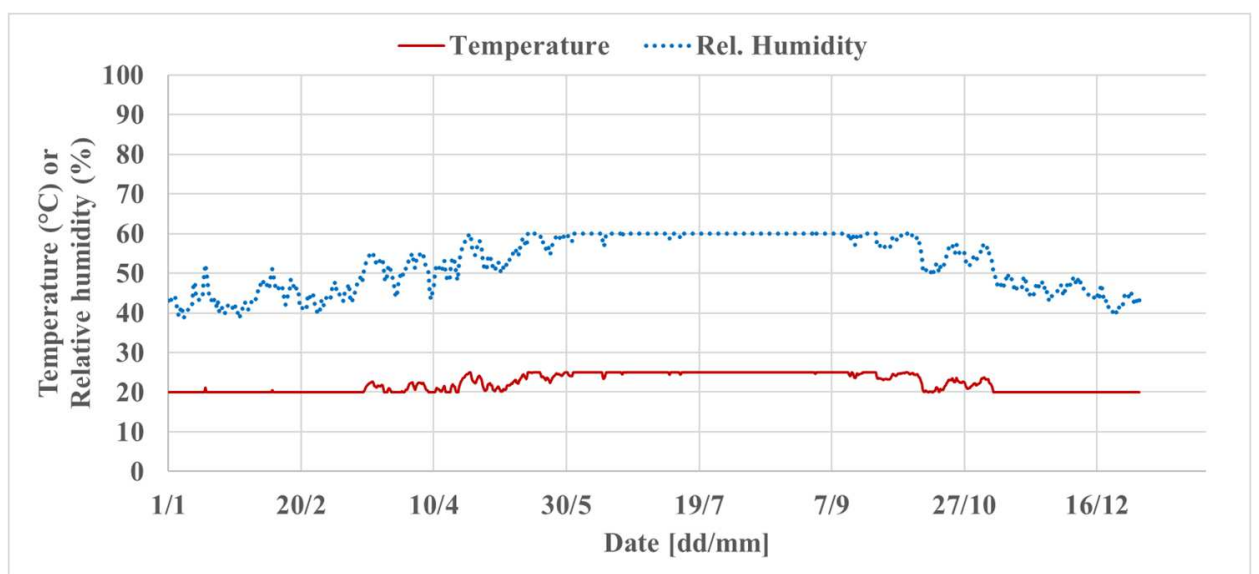

Figure 33: The interior air temperature and relative humidity for the city of Torino

As shown in Figure 32, the relative humidity behind the interior $A A B C$ insulation shows a very different behavior between the original model and the calibrated model. Unlike the original model, the $\mathrm{RH}$ shows a, relatively, rapid increase during the first two months till reaching a maximum value of around $85 \%$ and remains stable during the winter months before starts decreasing afterwards. The original model, which has a very tight vapour barrier $(m u=10000$ measured at lab-scale) at the inside, shows a slow increase in the $\mathrm{RH}$ during the winter season till reaching its maximum value of around $77 \%$ in the spring season before starts decreasing in the summer season.

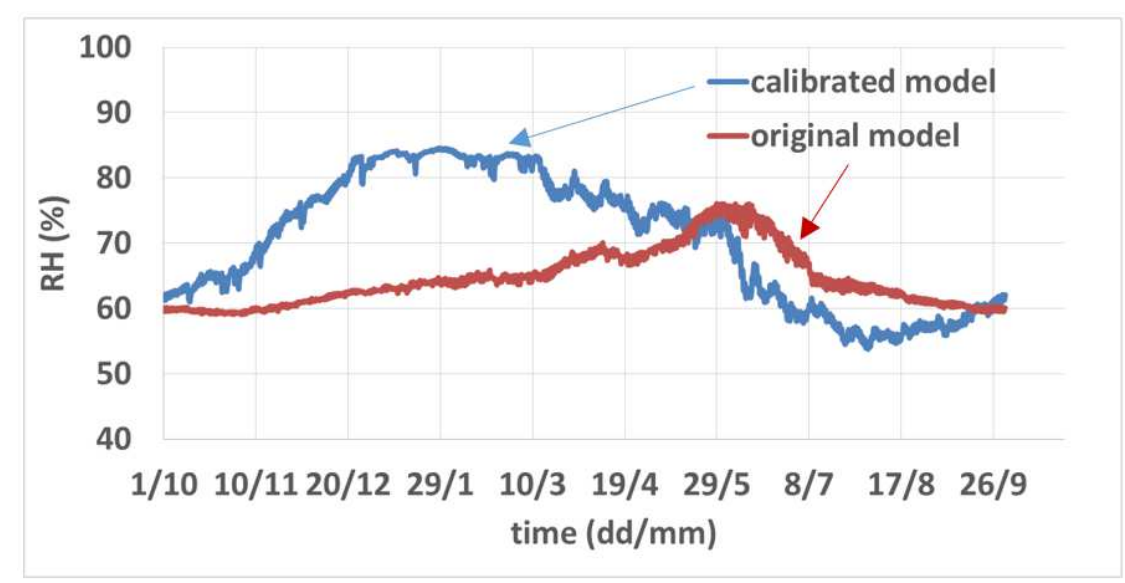

Figure 34: relative humidity behind the interior $A A B C$ insulation calculated by the original and the calibrated models (last year of simulation period)

\subsection{2-dimensional case}

In this case study, the externally insulated wall with the window reveal thermal bridge is considered. The initial and the boundary conditions are the same as those of the previous case study (1-D case). The relative humidity in the concrete layer at a position just near the window is shown in Figure 33 for two cases: No $(0 \mathrm{~cm})$ aerogel-based insulation on the window reveal and $1 \mathrm{~cm}$ aerogel-based insulation on the window reveal. The relative humidity is decreased significantly when $1 \mathrm{~cm}$ of the aerogel insulation is applied on the window reveal. It is clear from 
this simulation case that the aerogel-based insulation if applied even in very small thickness can reduce significantly the moisture risks. From a thermal perspective, the aerogel insulation on the reveal decreases the heat losses near the thermal bridge up to $40 \%$.

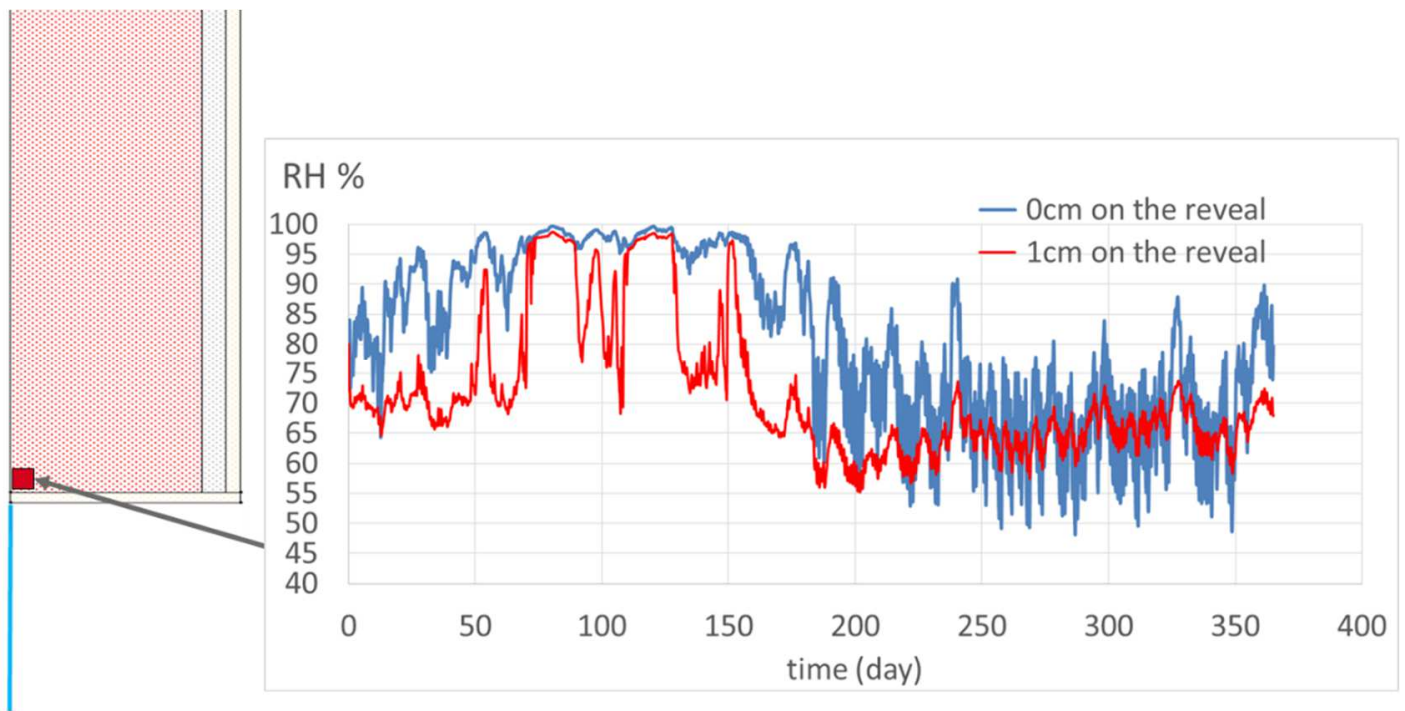

Figure 35: relative humidity near the window: without and with $1 \mathrm{~cm}$ of the aerogel insulation on the reveal

\section{Discussion and conclusion}

The objectives of this paper consisted in assessing the thermal and moisture performance of two envelopes insulated with aerogel-based systems, representing a typical refurbishment case, and to calibrate numerical models for heat and moisture transfer. One envelope is internally insulated while the other is externally insulated. The systems are lightweight with very good thermal performance. The internal insulation system includes a synthetic rubber layer acting as an integrated vapor barrier and as an acoustic layer as well.

The results showed that the external insulation system protects the wall against the moisture risks. For the internally insulated wall, relative humilities remain lower than $85 \%$ even when high moisture generation is present inside the test cell. However, as the moisture transfer within building envelopes is a slow physical phenomenon, long-term monitoring data is needed for assessment.

Concerning the thermal performance, the walls showed very good performance; however, the thermal conductivity of the aerogel panels is slightly higher than those measured at lab scale. The reason can be attributed to the presence of thermal bridges, to the effect of moisture content on thermal conductivity, and/or due to other issues related to the in-situ experimental set-up itself such as thermal contact resistant between the sensors and the wall material. The average method to calculate the in-situ thermal conductance need some time to converge and 
the period of data should be carefully chosen as to ensure a thermal gradient large enough between the indoor and outdoor environments.

The conclusion from the numerical modeling calibration is that the models constructed using lab-scale measured data can lead to significant errors in the results compared to in site real performance, mainly for moisture transfer. The results can be far enough from the in-situ measurements leading to a completely different behavior of the envelopes. A calibration step is necessary to allow the numerical models to reproduce the measurement values. In this paper, we used the parametric analysis to calibrate the numerical models. A first step includes identifying the most influential parameters on the model calibration results. Thanks to this analysis, it is possible to evaluate the influence of different parameters on the results. As a demonstration, the initial moisture content within the assembly changes deeply the results if not more than one year of monitoring data is used and the equilibrium is not reached. The thermal conductivity of the concrete hollow block, modeled in our case here as several layers of concrete and air layers, is essential to calibrate as thermal bridges exist within the concrete block itself. For the internally insulated wall, the water vapour diffusion resistance of the synthetic rubber has a major influence on the results. To have acceptable results, the factor should be reduced by 3.3 times its initial value obtained from lab-scale measurements. One possibility to explain this is that the material should be represented by smaller thickness, maybe due to irregularity of thickness of the material itself and/or at the installation site.

It is important to note that changing the materials properties (other than thermal conductivity) does not have a significant influence on the temperature results. Therefore, it is concluded from the parametric analysis that it is quite not so difficult to calibrate the models in terms of temperatures but much more difficult to calibrate it in terms of relative humidity as a lot of parameters can have a significant influence.

The parametric analysis is a good approach to identify the most influential parameters for model calibration. However, an automated optimization approach should be adopted to calibrate the heat and moisture numerical models as different combination of different variables can change the results. As a perspective of this study, the authors are working on coupling the numerical models with an optimization algorithm for the objective of model calibration.

\section{Acknowledgment}

The research leading to these results has been performed within the HOMESKIN project (http://homeskin.net/) and received funding from the European Community's Horizon 2020 Programme (H2020/2014-2020) under grant agreement $n^{\circ} 636709$. 
We highly acknowledge the help of Kévin Nocentini, from ARMINES/Mines ParisTech, and Marina Stipetic, from the Materials Testing Institute of the University of Stuttgart, for providing the lab-scale measurements.

\section{Reference}

[1] R. Galliano, K. Ghazi Wakili, T. Stahl, B. Binder, and B. Daniotti, "Performance evaluation of aerogel-based and perlite-based prototyped insulations for internal thermal retrofitting: HMT model validation by monitoring at demo scale," Energy Build., vol. 126, pp. 275-286, Aug. 2016.

[2] R. Garay Martinez, E. Goiti, G. Reichenauer, S. Zhao, M. Koebel, and A. Barrio, "Thermal assessment of ambient pressure dried silica aerogel composite boards at laboratory and field scale," Energy Build., vol. 128, pp. 111-118, Sep. 2016.

[3] E. Cuce and P. M. Cuce, "The impact of internal aerogel retrofitting on the thermal bridges of residential buildings: An experimental and statistical research," Energy Build., vol. 116, pp. 449454, Mar. 2016.

[4] Á. Lakatos, "Comprehensive thermal transmittance investigations carried out on opaque aerogel insulation blanket," Mater. Struct., vol. 50, no. 1, Feb. 2017.

[5] A. Sáez de Guinoa, D. Zambrana-Vasquez, A. Alcalde, M. Corradini, and I. Zabalza-Bribián, "Environmental assessment of a nano-technological aerogel-based panel for building insulation," $J$. Clean. Prod., vol. 161, pp. 1404-1415, Sep. 2017.

[6] M. Ibrahim, P. H. Biwole, E. Wurtz, and P. Achard, "A study on the thermal performance of exterior walls covered with a recently patented silica-aerogel-based insulating coating," Build. Environ., vol. 81, pp. 112-122, Nov. 2014.

[7] U. Berardi, "Aerogel-enhanced systems for building energy retrofits: Insights from a case study," Energy Build., vol. 159, pp. 370-381, Jan. 2018.

[8] C. Buratti, E. Moretti, and E. Belloni, "Aerogel Plasters for Building Energy Efficiency," in Nano and Biotech Based Materials for Energy Building Efficiency, F. Pacheco Torgal, C. Buratti, S. Kalaiselvam, C.-G. Granqvist, and V. Ivanov, Eds. Cham: Springer International Publishing, 2016, pp. $17-40$.

[9] C. Buratti, E. Moretti, E. Belloni, and F. Agosti, "Development of Innovative Aerogel Based Plasters: Preliminary Thermal and Acoustic Performance Evaluation," Sustainability, vol. 6, no. 9, pp. 58395852, Sep. 2014.

[10] M. Ibrahim, L. Bianco, O. Ibrahim, and E. Wurtz, "Low-emissivity coating coupled with aerogelbased plaster for walls' internal surface application in buildings: Energy saving potential based on thermal comfort assessment," J. Build. Eng., vol. 18, pp. 454-466, Jul. 2018.

[11] M. Dowson, I. Pegg, D. Harrison, and Z. Dehouche, "Predicted and in situ performance of a solar air collector incorporating a translucent granular aerogel cover," Energy Build., vol. 49, pp. 173187, Jun. 2012.

[12] K. McEnaney, L. Weinstein, D. Kraemer, H. Ghasemi, and G. Chen, "Aerogel-based solar thermal receivers," Nano Energy, vol. 40, pp. 180-186, Oct. 2017. 
[13] M. Ibrahim, E. Wurtz, P. H. Biwole, and P. Achard, "Transferring the south solar energy to the north facade through embedded water pipes," Energy, vol. 78, pp. 834-845, Dec. 2014.

[14] M. Ibrahim, E. Wurtz, J. Anger, and O. Ibrahim, "Experimental and numerical study on a novel low temperature façade solar thermal collector to decrease the heating demands: A south-north pipeembedded closed-water-loop system," Sol. Energy, vol. 147, pp. 22-36, May 2017.

[15] K. G. Wakili et al., "High Performance Aerogel Containing Plaster for Historic Buildings with Structured Façades," Energy Procedia, vol. 78, pp. 949-954, Nov. 2015.

[16] M. Ibrahim, P. H. Biwole, P. Achard, E. Wurtz, and G. Ansart, "Building envelope with a new aerogelbased insulating rendering: Experimental and numerical study, cost analysis, and thickness optimization," Appl. Energy, vol. 159, pp. 490-501, Dec. 2015.

[17] "Ibrahim, M., Biwole, P. H., Achard, P., \& Wurtz, E. (2015). Aerogel-based materials for improving the building envelope's thermal behavior: a brief review with a focus on a new aerogel-based rendering. In Energy Sustainability Through Green Energy (pp. 163-188). Springer, New Delhi.," .

[18] M. Ibrahim, P. H. Biwole, E. Wurtz, and P. Achard, "Limiting windows offset thermal bridge losses using a new insulating coating," Appl. Energy, vol. 123, pp. 220-231, Jun. 2014.

[19] "FIXIT

222.

https://www.fixit.ch/var/fixitgruppe/storage/ilcatalogue/files/pdf/CHFR/Fiche_technique_FT_Fixit 2222_Aerogel_Enduit_thermo-isolant_haute_per_DC0017313.PDF (accessed on October 2018."

[20] K.-J. Lee, Y.-J. Choe, Y. H. Kim, J. K. Lee, and H.-J. Hwang, "Fabrication of silica aerogel composite blankets from an aqueous silica aerogel slurry," Ceram. Int., vol. 44, no. 2, pp. 2204-2208, Feb. 2018.

[21] "Aspen,

Spaceloft. https://www.aerogel.com/_resources/common/userfiles/file/Data\%20Sheets/Spaceloft-EuropeanDatasheet-EN.pdf (accessed on October 2018)."

[22] "Cabot. Aerogel Blanket. http://www.cabotcorp.com/solutions/products-plus/aerogel/blanket (accessed on October 2018)."

[23] S. Fickler, B. Milow, L. Ratke, M. Schnellenbach-Held, and T. Welsch, "Development of High Performance Aerogel Concrete," Energy Procedia, vol. 78, pp. 406-411, Nov. 2015.

[24] T. Gao, B. P. Jelle, A. Gustavsen, and S. Jacobsen, "Aerogel-incorporated concrete: An experimental study," Constr. Build. Mater., vol. 52, pp. 130-136, Feb. 2014.

[25] S. Ng, B. P. Jelle, L. I. C. Sandberg, T. Gao, and Ó. H. Wallevik, "Experimental investigations of aerogel-incorporated ultra-high performance concrete," Constr. Build. Mater., vol. 77, pp. 307-316, Feb. 2015.

[26] C. Buratti and E. Moretti, "Experimental performance evaluation of aerogel glazing systems," Appl. Energy, vol. 97, pp. 430-437, Sep. 2012.

[27] C. Buratti and E. Moretti, "Glazing systems with silica aerogel for energy savings in buildings," Appl. Energy, vol. 98, pp. 396-403, Oct. 2012.

[28] T. Gao, B. P. Jelle, T. Ihara, and A. Gustavsen, "Insulating glazing units with silica aerogel granules: The impact of particle size," Appl. Energy, vol. 128, pp. 27-34, Sep. 2014. 
[29] "Bhuiya, M. M. H., Anderson, A. M., Carroll, M. K., Bruno, B. A., Ventrella, J. L., Silberman, B., \& Keramati, B. (2016). Preparation of monolithic silica aerogel for fenestration applications: scaling up, reducing cycle time, and improving performance. Industrial \& Engineering Chemistry Research, 55(25), 6971-6981."

[30] K. Nocentini, P. Achard, and P. Biwole, "Hygro-thermal properties of silica aerogel blankets dried using microwave heating for building thermal insulation," Energy Build., vol. 158, pp. 14-22, Jan. 2018.

[31] M. Ibrahim, M. Stipetic, E. Wurtz, and J. Frick, "Mould growth assessment of internally insulated advanced envelopes: A parametric study and the notion of the multi-variable design-assessment charts," Proceedings of Building Simulation 2017 of the International Building Performance Simulation Association, San Francisco, USA

[32] J. R. Philip and D. A. De Vries, "Moisture movement in porous materials under temperature gradients," Trans. Am. Geophys. Union, vol. 38, no. 2, p. 222, 1957.

[33] D. A. De Vries, "Simultaneous transfer of heat and moisture in porous media," Trans. Am. Geophys. Union, vol. 39, no. 5, p. 909, 1958.

[34] "A.V. Luikov(1964). Heat and mass transfer in capillary-porous bodies. In Advances in heat transfer (Vol. 1, pp. 123-184). Elsevier."

[35] Mendes, N., Chhay, M., Berger, J., \& Dutykh, D. (2017). Numerical methods for diffusion phenomena in building physics: A practical introduction. PUCPRess. .

[36] "B. Bauklimatik. Dresden. Simulation program for the calculation of coupled heat, moisture, air, pollutant, and salt transport. http://www.bauklimatikdresden.de/delphin/index.php?aLa=en, 2011. 5."

[37] C. Rode and K. Grau, "Whole Building Hygrothermal Simulation Model," ASHRAE Trans., p. 12.

[38] "Burch, D. M., \& Chi, J. (1997). MOIST: A PC program for predicting heat and moisture transfer in building envelopes: Release 3.0. US Department of Commerce, National Institute of Standards and Technology."

[39] "IBP, WUFI@ Pro version 5.3, Fraunhofer Institute for Building Physics, Holzkirchen, Germany."

[40] "Sasic Kalagasidis A (2004). HAM-Tools: an integrated simulation tool for heat, air and moisture transfer analyses in building physics. PhD Dissertation. Chalmers University of Technology, Gothenburg, Sweden."

[41] M. Woloszyn and C. Rode, "Tools for performance simulation of heat, air and moisture conditions of whole buildings," Build. Simul., vol. 1, no. 1, pp. 5-24, Mar. 2008.

[42] E. Lucchi et al., "Thermal performance evaluation and comfort assessment of advanced aerogel as blown-in insulation for historic buildings," Build. Environ., vol. 122, pp. 258-268, Sep. 2017.

[43] M. Ibrahim, E. Wurtz, P. H. Biwole, P. Achard, and H. Sallee, "Hygrothermal performance of exterior walls covered with aerogel-based insulating rendering," Energy Build., vol. 84, pp. 241-251, Dec. 2014.

[44] J. Wernery, A. Ben-Ishai, B. Binder, and S. Brunner, "Aerobrick - An aerogel-filled insulating brick," Energy Procedia, vol. 134, pp. 490-498, Oct. 2017. 
[45] G. Masera et al., "Development of a Super-insulating, Aerogel-based Textile Wallpaper for the Indoor Energy Retrofit of Existing Residential Buildings," Procedia Eng., vol. 180, pp. 1139-1149, 2017.

[46] K. Ghazi Wakili, C. Dworatzyk, M. Sanner, A. Sengespeick, M. Paronen, and T. Stahl, "Energy efficient retrofit of a prefabricated concrete panel building (Plattenbau) in Berlin by applying an aerogel based rendering to its façades," Energy Build., vol. 165, pp. 293-300, Apr. 2018.

[47] T. Stahl, K. Ghazi Wakili, S. Hartmeier, E. Franov, W. Niederberger, and M. Zimmermann, "Temperature and moisture evolution beneath an aerogel based rendering applied to a historic building," J. Build. Eng., vol. 12, pp. 140-146, Jul. 2017.

[48] L. Bianco, P. Schneuwly, E. Wurtz, and A. Brun, "Design of a New Full-scale Facility for Building Envelope Test: FACT (FACade Tool)," Energy Procedia, vol. 111, pp. 256-266, Mar. 2017.

[49] "ISO 9869-1:2014. Thermal insulation -- Building elements -- In-situ measurement of thermal resistance and thermal transmittance -- Part 1: Heat flow meter method."

[50] "Sensirion, The sensor company. Digital Humidity Sensor SHT7x (RH/T). https://www.sensirion.com/products/humidity-sensors/pintype-digital-humidity-sensors/ (date of last access: February 2017)."

[51] "Wimesure. http://www.wimesure.fr/cbx/index.htm (date of last access: February 2017)."

[52] E. Vereecken and S. Roels, "Review of mould prediction models and their influence on mould risk evaluation," Build. Environ., vol. 51, pp. 296-310, May 2012.

[53] H. Vitanen, "Factors affecting the development of mould and brown rot decay in wooden material and wooden structures: Effect of humidity, temperature and exposure time." [Online]. Available: https://elibrary.ru/item. asp?id=6878045. [Accessed: 12 -Oct-2018].

[54] "Ojanen T, Peuhkuri R, Viitanen H, Lähdesmäki K, Vinha J, Salminen K (2011). Classification of material sensitivity e new approach for mould growth modeling. In: 9th Nordic symposium on building physics, vol. 2, 867-874."

[55] H. Viitanen, T. Ojanen, R. Peuhkuri, J. Vinha, K. Lähdesmäki, and K. Salminen, "Mould Growth Modelling to Evaluate Durability of Materials," p. 8, 2011.

[56] "EN 15026 (2007). Hygrothermal Performance of Building Components and Building ElementsAssessment of Moisture Transfer by Numerical Simulation."s 